\title{
Nonvisual Complex Spike Signals in the Rabbit Cerebellar Flocculus
}

\author{
Beerend H. J. Winkelman, Tim Belton, Minah Suh, Michiel Coesmans, Menno M. Morpurgo, and John I. Simpson \\ Department Physiology and Neuroscience, New York University School of Medicine, New York, New York 10016
}

In addition to the well-known signals of retinal image slip, floccular complex spikes (CSs) also convey nonvisual signals. We recorded eye movement and CS activity from Purkinje cells in awake rabbits sinusoidally oscillated in the dark on a vestibular turntable. The stimulus frequency ranged from 0.2 to $1.2 \mathrm{~Hz}$, and the velocity amplitude ranged from 6.3 to $50 \%$. The average CS modulation was evaluated at each combination of stimulus frequency and amplitude. More than $75 \%$ of the Purkinje cells carried nonvisual CS signals. The amplitude of this modulation remained relatively constant over the entire stimulus range. The phase response of the CS modulation in the dark was opposite to that during the vestibulo-ocular reflex (VOR) in the light. With increased frequency, the phase response systematically shifted from being aligned with contraversive head velocity toward peak contralateral head position. At fixed frequency, the phase response was dependent on peak head velocity, indicating a system nonlinearity. The nonvisual CS modulation apparently reflects a competition between eye movement and vestibular signals, resulting in an eye movement error signal inferred from nonvisual sources. The combination of this error signal with the retinal slip signal in the inferior olive results in a net error signal reporting the discrepancy between the actual visually measured eye movement error and the inferred eye movement error derived from measures of the internal state. The presence of two error signals requires that the role of CSs in models of the floccular control of VOR adaption be expanded beyond retinal slip.

Key words: accessory optic system; climbing fiber; complex spike; inferior olive; prepositus hypoglossi; Purkinje cell

\section{Introduction}

Complex spikes (CSs) are pronounced composite potentials evoked by the climbing fiber input to cerebellar Purkinje cells at a low rate of approximately one spike per second (Granit and Phillips, 1956; Eccles et al., 1966; Thach, 1967). CS activity of Purkinje cells in the flocculus of the cerebellum is well known to be modulated by image motion across the retina (Simpson and Alley,

\section{Received July 19, 2013; revised Jan. 16, 2014; accepted Jan. 18, 2014.}

Author contributions: B.H.J.W., T.B., and J.I.S. designed research; B.H.J.W., T.B., M.S., M.C., M.M.M., and J.I.S. performed research; B.H.J.W. contributed unpublished reagents/analytic tools; B.H.J.W. analyzed data; B.H.J.W., T.B., and J.I.S. wrote the paper.

This work was supported by NIH Grants NS-13742 and DC-03284. We thank Alfred and Akos Benedek for superb technical support.

The authors declare no competing financial interests.

Correspondence should be addressed to either of the following: Dr. Beerend H.J. Winkelman, Department of Cerebellar Coordination and Cognition, Netherlands Institute for Neuroscience, Meibergdreef 47, 1105 BA, Amsterdam, The Netherlands, E-mail: b.winkelman@herseninstituut.knaw.nl; or Dr. John I. Simpson, Department of Physiology \& Neuroscience, New York University School of Medicine, 550 First Avenue, New York, NY 10016, E-mail: john.simpson@nyumc.org.

B. H. J. Winkelman's present address: Department of Cerebellar Coordination and Cognition, Netherlands Institute for Neuroscience, Meibergdreef 47, 1105 BA, Amsterdam, The Netherlands.

T. Belton's present address: Department of Biochemistry and Molecular Biology, Columbia University, New York, NY 10032.

M. Suh's present address: Department of Biological Science, Sungkyunkwan University, Suwon, 440-746, Korea. M. Coesmans' present address: Delta Psychiatric Center, Maasstadweg 96,3079 DZ, Rotterdam, The Netherlands.

M. M. Morpurgo's present address: Department of Radiology, Spijkenisse Medisch Centrum, PO Box 777, 3200 GA Spijkenisse, The Netherlands.

J. I. Simpson's present address: Department of Physiology and Neuroscience, New York University School of Medicine, 550 First Avenue, New York, NY 10016

DOI:10.1523/JNEUROSCI.3080-13.2014

Copyright $\odot 2014$ the authors $\quad 0270-6474 / 14 / 343218-13 \$ 15.00 / 0$
1974; Graf et al., 1988; Stone and Lisberger, 1990), as is readily observable during passive whole-body rotation in the light. In contrast, CS modulation also occurs during whole-body rotation in complete darkness (Ghelarducci et al., 1975; Blanks and Precht, 1983; Leonard and Simpson, 1986; De Zeeuw et al., 1995). The visual CS response in the flocculus has been relatively well characterized and features prominently in cerebellar motor learning models of the vestibulo-ocular reflex (VOR) based upon Ito's "flocculus hypothesis" (Ito, 1972, 1982). Ito initially proposed the adaptation of the VOR as a specific behavior with which to evaluate the cerebellar motor learning hypotheses of Marr and Albus (Marr, 1969; Albus, 1971). These hypotheses advanced the notion that the climbing fibers that project to the cerebellar cortex and induce complex spikes in Purkinje cells carry error signals that shape cerebellar output through synaptic plasticity at the parallel fiber to Purkinje cell synapse. The retinal slip signal identified in floccular complex spike activity can be viewed as a well-defined example of an error signal, reporting visually detected errors in compensatory eye movement performance. The nonvisual CS response, recorded during vestibular stimulation in darkness and transmitted by the same climbing fibers that mediate the visual CS response, has however received scant attention and is omitted from most structural and functional models that include the flocculus.

In the present study, we found that approximately threefourths of the visual climbing fibers in the flocculus also carry nonvisual signals. To form a more complete picture of the signals carried by climbing fibers to the flocculus, we have conducted a 
A1

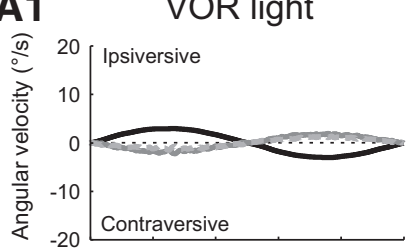

B1

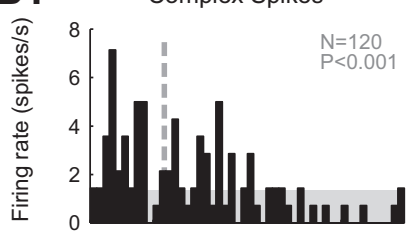

C1

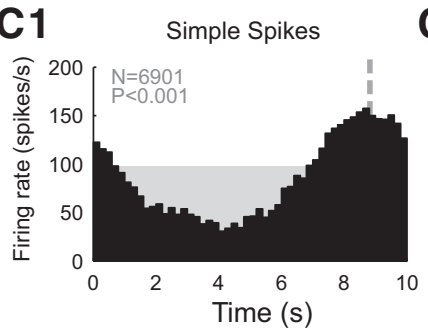

A2

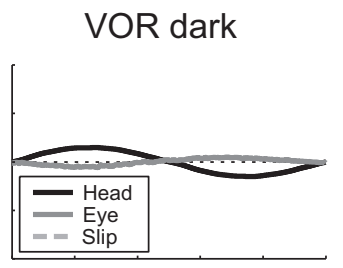

B2

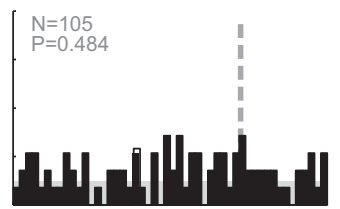

C2

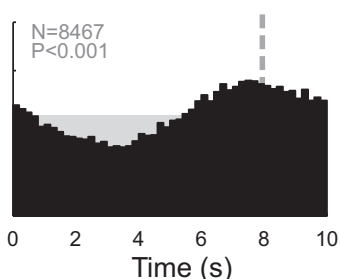

A3

VOR light

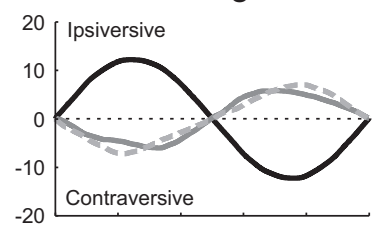

A4

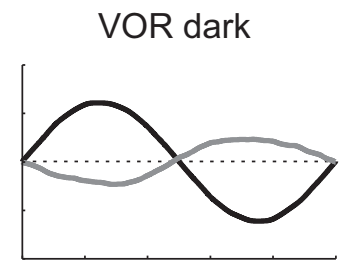

B3

Complex Spikes

B4

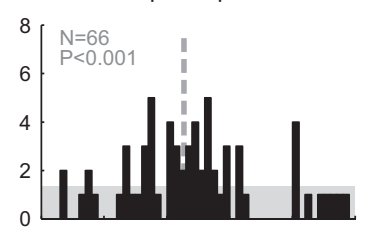

C3

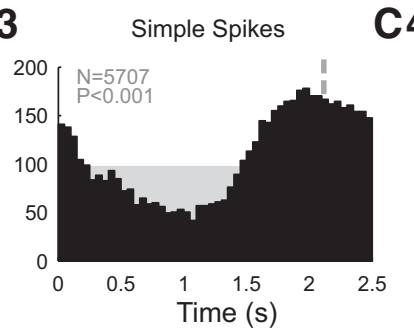

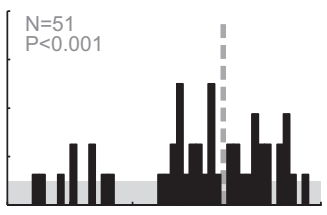

C4

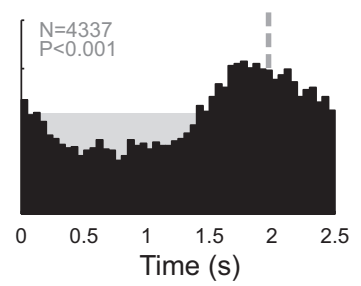

Figure 1. Histograms of single-unit activity of an individual floccular VA Purkinje cell recorded during vestibular stimulation in the light (columns 1 and 3 ) and in the dark (columns 2 and 4). Columns 1 and 2 show the responses to low-frequency, low-velocity rotation $\left(0.1 \mathrm{~Hz}\right.$ at $\left.3.1^{\circ} / \mathrm{s}\right)$ about the vertical axis. In columns 3 and 4 , the stimulus parameters were increased $\left(0.4 \mathrm{~Hz}\right.$ at $\left.12.5^{\circ} / \mathrm{s}\right)$. $\boldsymbol{A}$, Average angular velocity of the head (black line), the slow-phase eye movement (gray line), and the residual retinal image slip (light-gray dashed line). $\boldsymbol{B}$, Average CS firing rate. $\boldsymbol{C}$, Average simple spike firing rate. The level of the shaded area indicates the spontaneous firing rate; the vertical dashed line indicates the circular mean of the spike events. Spike count ( $M$ ) and significance of modulation ( $P$, Rayleigh's $R^{2}$ test) are indicated in gray in each panel.

quantitative characterization of the frequency and velocity dependence of the nonvisual CS modulation recorded in the awake, behaving rabbit. The presence of both visual and nonvisual modulation is consistent with models of adaptation that include two sources of error signals: one reporting the measured sensory error and the other reporting an internal inferred estimate of the error. A preliminary report of part of this study has been published in short form (Simpson et al., 2002).

\section{Materials and Methods}

Animal preparation. Ten Dutch belted rabbits of either sex were prepared for chronic recording using sterile surgical techniques. Anesthesia was induced using a mixture of ketamine $(32 \mathrm{mg} / \mathrm{kg}$, i.m.), acepromazine $(0.32$ $\mathrm{mg} / \mathrm{kg}$, i.m.), and xylazine $(5.0 \mathrm{mg} / \mathrm{kg}$, i.m.) and maintained by regular supplementation $(9 \mathrm{mg} / \mathrm{kg}$ ketamine, $0.09 \mathrm{mg} / \mathrm{kg}$ acepromazine, $2.0 \mathrm{mg} / \mathrm{kg}$ xylazine) administered every $30-45 \mathrm{~min}$. An acrylic head fixation pedestal was attached to the top of the skull using stainless steel screws. A craniotomy was made over the left paramedian lobule of the cerebellum, over which a recording chamber was centered to permit electrode access to the left flocculus. To enable accurate measurement of eye position, a scleral search coil (Robinson, 1963; Judge et al., 1980) was implanted around the left eye. The search coil consisted of three loops of insulated stainless steel wire (Cooner AS632) that was threaded under the conjunctiva and the superior and inferior rectus and inferior oblique muscles of the eye, parallel to the limbus. The animal use protocol was approved by the Institutional Animal Care and Use Committee at the New York University School of Medicine.

Vestibular and optokinetic stimulation. Experiments were started after a recovery period of at least 1 week. The awake behaving animal was mounted on a servo-controlled turntable using the acrylic ped- estal to hold the head. Vestibular stimulation was provided by sinusoidal oscillation of the turntable. An optokinetic drum (diameter 85 $\mathrm{cm}$ ), decorated with white graffiti on a black background, was used for optokinetic stimulation and also served as the earth-stationary visual surround during turntable rotation. The drum extended from the zenith to $25^{\circ}$ below the visual horizon. Both turntable and drum rotated sinusoidally about the vertical axis, which intersected the interaural and the rostrocaudal axis of the animal's head. With the nasal bone at a $57^{\circ}$ angle to the horizon, near-optimal stimulation of the horizontal semicircular canal with table rotation was achieved (Soodak and Simpson, 1988).

Stimulus conditions comprised a set of six frequencies $(0.2,0.4,0.6$, $0.8,1.0$, and $1.2 \mathrm{~Hz}$ ). At each frequency stimulus amplitudes comprised five peak velocities $(6.3 \% \mathrm{~s}, 12.5 \% \mathrm{~s}, 25.0 \% \mathrm{~s}, 37.5 \% \mathrm{~s}$, and $50.0 \% \mathrm{~s})$. The typical recording duration was $100 \mathrm{~s}$ for each stimulus condition. Many cells were tested multiple times with the same stimulus condition to improve the CS sampling size. Occasionally, the frequency/amplitude combination of $0.1 \mathrm{~Hz}$ at $3.1 \%$ sas used for comparative purposes. Because of the increased risk of losing well isolated cells during vestibular stimulation at high frequencies and velocities, most cells were initially tested at the lower end of the stimulus range. The standard frequency/ velocity combinations used on nearly all cells to test for nonvisual CS modulation were 0.4 or $0.6 \mathrm{~Hz}$, at peak velocities of either $12.5 \%$ s or $25.0 \%$ s.

Electrophysiology. Borosilicate glass microelectrodes filled with $2 \mathrm{M}$ $\mathrm{NaCl}$ and saturated with fast green FCF dye were advanced through small openings in the dura, using a hydraulic micropositioner attached to the recording chamber. The electrodes had tip diameters of $2-4 \mu \mathrm{m}$ and resistances of 3-6 $\mathrm{m} \Omega$. The chamber was positioned to allow rostrocau- 
A1

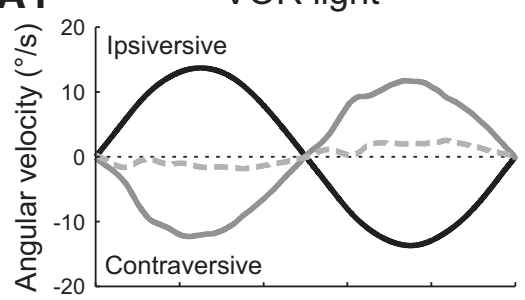

B1

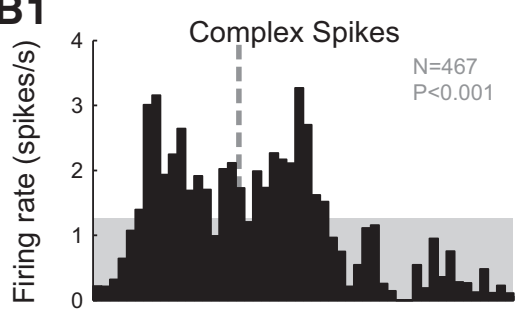

C1

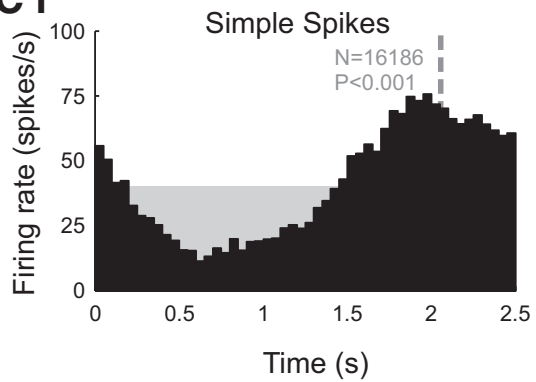

A2

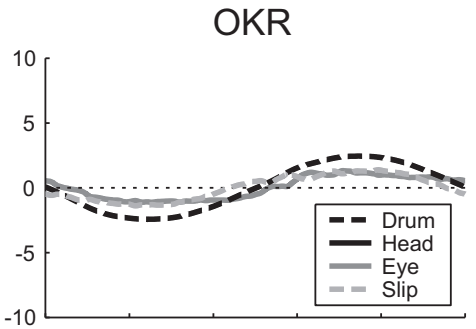

B2

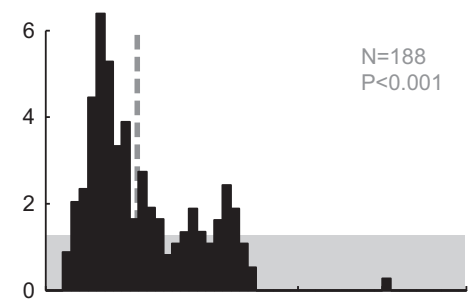

C2

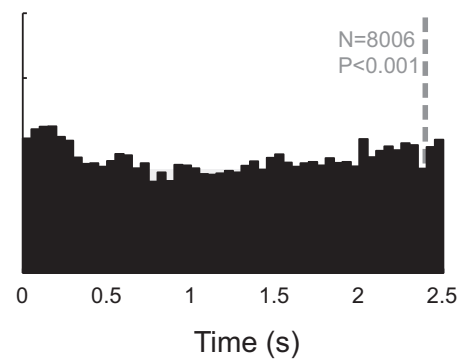

A3

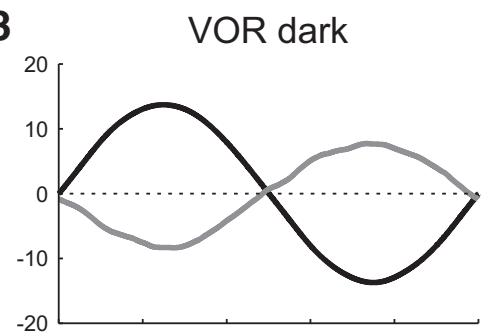

B3

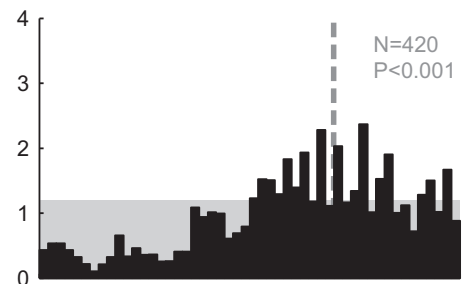

C3

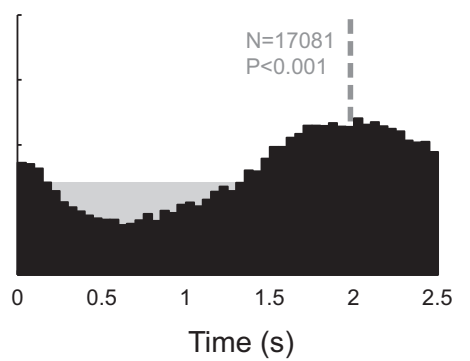

Figure 2. Histograms of the single-unit activity of an individual floccular VA Purkinje cell recorded during three different stimulus conditions: vestibular stimulation in the light (column 1), optokinetic stimulation (column 2), and vestibular stimulation in the dark (column 3). The stimulus frequency was $0.4 \mathrm{~Hz}$. A, Average angular velocity of the head (black line), the slow-phase eye movement (gray line), and the residual retinal image slip (light-gray dashed line). $\boldsymbol{B}$, Average CS firing rate. $\boldsymbol{C}$, Average simple spike firing rate. The amplitude of the optokinetic stimulus ( $\boldsymbol{A}_{2}$, black dashed line) was set to $2.5^{\circ} / \mathrm{s}$, so that the magnitude of the retinal image slip (light gray dashed line) approximately matched that of the slip during vestibular stimulation in the light $\left(\boldsymbol{A}_{\boldsymbol{1}}\right)$.

dal and mediolateral exploration across all folia of the flocculus, which was reached at $\sim 7 \mathrm{~mm}$ below the dura. Single-unit activity was preamplified $(1000 \times)$, notch filtered at $32 \mathrm{kHz}$, and bandpass filtered with cutoff frequencies at $10 \mathrm{~Hz}$ and $10 \mathrm{kHz}$. Simple spikes (SSs) and CSs were detected using window discriminators. SS activity was determined to be from the same Purkinje cell as the recorded CS activity by online monitoring of the post-CS pause in SS activity (Eccles et al., 1966; Thach, 1967; Sato et al., 1992).

Each Purkinje cell was categorized according to the axis of bestresponse of its visual CS modulation (Graf et al., 1988; Van der Steen et al., 1994) using a hand held large-field optokinetic stimulus. We focused on those Purkinje cells whose CS activity was most increased by temporal to nasal movement of the visual field of the ipsilateral eye (vertical axis or VA cells). For comparison, we occasionally recorded the responses of Purkinje cells whose CS activity was best modulated by horizontal axis rotation of the visual field (horizontal axis or HA cells). Besides vestibular stimulation in the dark, each cell was also tested with vestibular stimuli in the light and/or optokinetic stimuli to characterize the response in the presence of vision.

Data acquisition. Table and drum positions were measured with precision potentiometers. Eye position was measured using the implanted search coil, which was located at the center of the magnetic field generated by 2 pairs of field driver coils that alternated in spatiotemporal quadrature at $32 \mathrm{kHz}$. The eye coil signal was calibrated at the beginning of each recording session by rotating the driver coils about the eye while the animal maintained a stationary, centered eye position. Position signals were sampled by a 1401plus data acquisition system (Cambridge Electronic Design) at $3331 / 3 \mathrm{~Hz}$. The movement of the turntable and drum was controlled using a custom graphical user interface written for the Spike2 software that controlled the CED data acquisition system. All recorded signals as well as the presence of a post-CS SS pause were monitored online.

Data analysis. All offline processing and analysis were performed using custom routines written for MATLAB (MathWorks). Table, drum, and eye position data were resampled to $1 \mathrm{kHz}$, smoothed using a Gaussian filter (10 Hz cutoff frequency), and differentiated to obtain angular velocity. Within each trial, composed of a particular frequency/amplitude combination, episodes containing recording artifacts were excluded. Stimulus amplitudes of the table and drum were verified using sinusoidal fits on the average velocity profiles similar to the eye movement analysis described below. A small subset of files in which the measured average table amplitude was $15 \%$ larger than the commanded table amplitude, which was caused by a temporary drift in table calibration in the early experiments, was removed from the total dataset. Furthermore, trials that contained $<25$ complex spikes were excluded, as well as trials in which it was impossible to construct an eye velocity average over a full cycle because of excessive occurrence of fast-phases and/or recording artifacts.

Saccadic eye movements and blinks were excluded from the eye movement averages. Saccadic eye movements were detected using a datadependent eye acceleration threshold set at 5 times the SD of the slow-phase eye acceleration distribution. An estimate of this SD was computed from the full-width at half maximum of the eye acceleration distribution divided by a proportionality constant of $2 \sqrt{2 \log 2}$. Data exclusion margins enclosing detected saccades extended $100 \mathrm{~ms}$ on each side of saccade onsets and offsets.

Trigger marks indicated table/drum velocity zero crossings preceding the ipsilateral table swing or the contralateral drum swing. The instantaneous phase angle of the stimulus $\theta_{t}$ was defined relative to the preceding 


\section{A1}

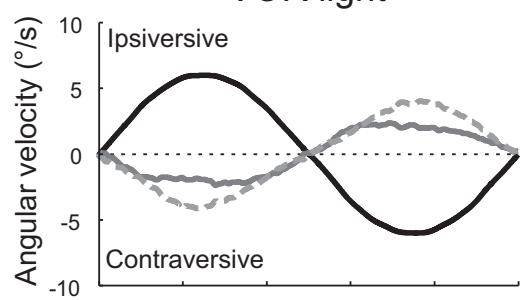

B1

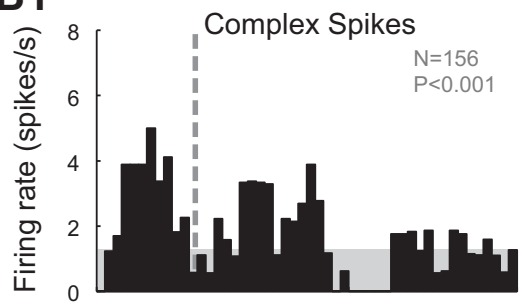

C1

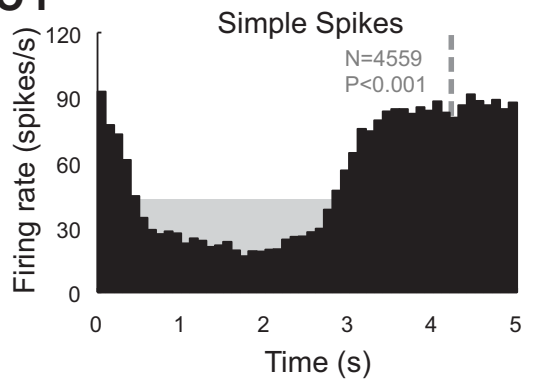

A2

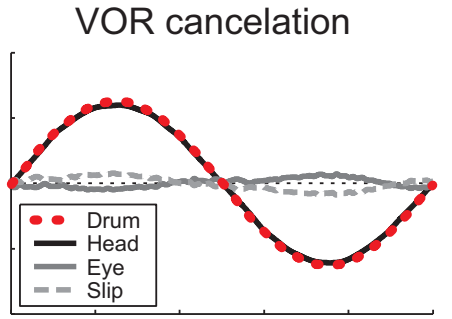

B2

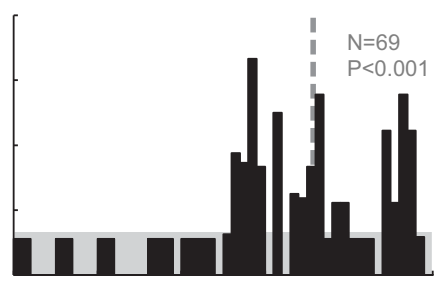

C2

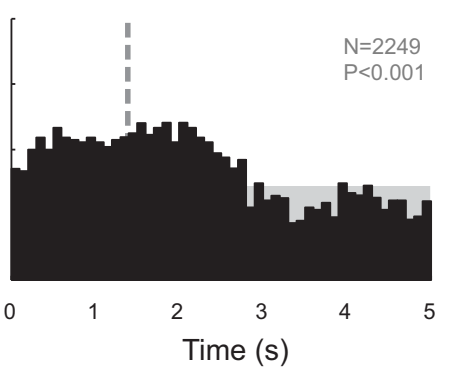

A3

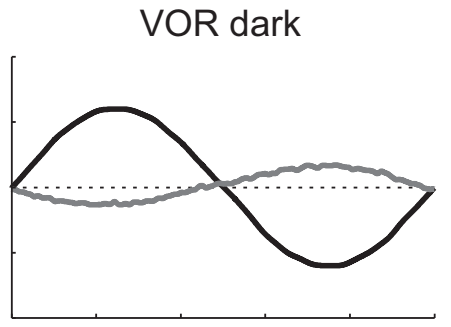

B3

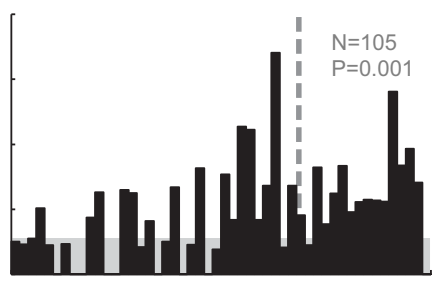

C3

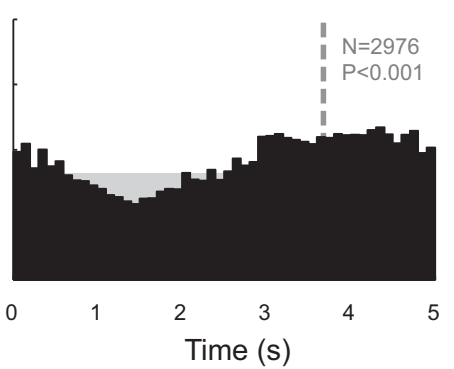

Figure 3. Histograms of single-unit activity of a floccular VA Purkinje cell recorded during vestibular stimulation $\left(0.2 \mathrm{~Hz}, 6.3^{\circ} / \mathrm{s}\right)$ under three different visual conditions: in the light with a stationary visual surround (column 1), in the light with a visual surround that moved in phase with the turntable (VOR cancellation, column 2 ), and in the dark (column 3 ). $\boldsymbol{A}$, Average angular velocity of the head (black line), the slow-phase eye movement (gray line), and the residual retinal image slip (light-gray dashed line). $\boldsymbol{B}$, Average $(S$ firing rate. $\boldsymbol{C}$, Average simple spike firing rate. The average angular velocity of the optokinetic drum is indicated with the red dashed line in $\boldsymbol{A}_{\mathbf{2}}$.

trigger time $t_{0}$ so that $\theta_{t}=2 \pi f\left(t-t_{0}\right) \bmod 2 \pi$, where $f$ is the stimulus frequency. Table, drum, and eye velocity were averaged over all $N$ cycles demarcated by trigger marks. The amplitude and phase angle of the table, drum, or eye movement response was computed using linear regression (Stahl and Simpson, 1995) of angular velocity to in-phase and quadrature components of the stimulus velocity of the form as follows:

$$
\hat{y}_{t}=\alpha+\beta_{1} \cos \theta_{t}+\beta_{2} \sin \theta_{t}
$$

where $\hat{y}_{t}$ represents eye velocity at time $t$. The bias term $\alpha$ accounts for the average drift, which was on average $\sim 0$. Amplitude $(\bar{A})$ was then calculated as follows:

$$
\bar{A}=\sqrt{\beta_{1}^{2}+\beta_{2}^{2}}
$$

and phase angle $(\bar{\theta})$ as follows:

$$
\bar{\theta}=\arctan \left(\beta_{2} / \beta_{1}\right)+k \pi
$$

where

$$
k= \begin{cases}+1 & \text { if } \beta_{1}<0 \text { and } \beta_{2} \geq 0 \\ -1 & \text { if } \beta_{1}<0 \text { and } \beta_{2}<0 \\ 0 & \text { if } \beta_{1} \geq 0\end{cases}
$$

In this convention, phase lead is positive and phase lag negative (De Zeeuw et al., 1995).

Spike analysis. Both amplitude and phase of the CS modulation were determined using standard vector averaging methods (Goldberg and Brown, 1969; Yin and Kuwada, 1983; Mardia and Jupp, 1999). In the most basic form of vector averaging, each spike occurrence at time $t_{i}$ defines a unit vector $x_{i}$ with phase angle $\theta_{i}$, corresponding to the instantaneous phase angle of the stimulus. The magnitude, $\bar{R}_{c s}=|\bar{x}|$, and angle, $\bar{\theta}_{c s}=\arg (\bar{x})$, of the vector average $\bar{x}$ over all $n$ CSs are proportional to, respectively, the amplitude and phase angle of the least-squares fit of a cosine function to the CS firing rate. Consequently, the cosine component $\bar{C}_{c s}=\bar{R}_{c s} \cos \bar{\theta}_{c s}$ and sine component $\bar{S}_{c s}=\bar{R}_{c s} \sin \bar{\theta}_{c s}$ of the vector average $\bar{x}$ are proportional to, respectively, the coefficients $b_{1}$ and $b_{2}$ described above, but with CS firing rate as the dependent variable, where the proportionality constant equals twice the mean CS firing rate. Modulation depth, $\bar{A}_{c s}=2 \bar{R}_{c s}$, expressed the modulation amplitude relative to the mean firing rate. The average modulation depth and modulation phase angle of all recorded cells were calculated using the means of $\bar{C}$ and $\bar{S}$. Error bars indicate the SEM, unless indicated otherwise. The SEM for phase angles was calculated from the circular SD (Mardia and Jupp, 1999).

When the phase response of a system is a linear function of angular frequency $\omega$, all components of the input signal are delayed equally in the output signal. The extent of the delay is proportional to the slope of the phase response as follows:

$$
\tau_{g}(\omega)=-\frac{d \theta(\omega)}{d \omega}
$$

The group delay of the CS signal over the stimulus frequency range was determined from the slope of the least-squares fit of a linear function to the phase response values. We used nested optimization to find the slopes for each stimulus frequency series with constant peak-velocity given a common intercept at the ordinate.

Statistics. For individual cells, the CS activity during stimulation was tested for significant modulation with Rayleigh's $R^{2}$ test, which uses $2 n \bar{R}_{c s}^{2}$ as the test statistic, taking modulation depth $\left(\bar{R}_{c s}\right.$, effect size $)$ and the number of spikes ( $n$, sample size) as parameters (Mardia and Jupp, 
A1

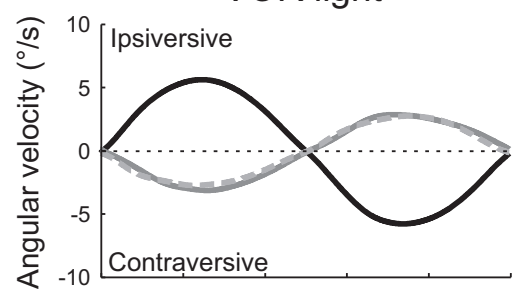

B1

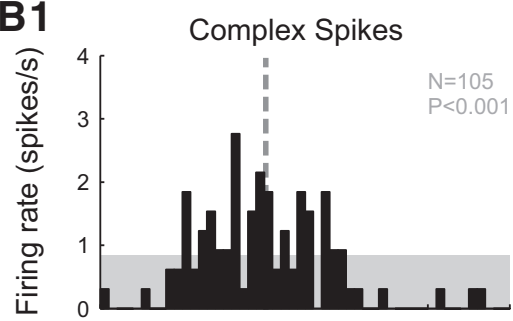

C1

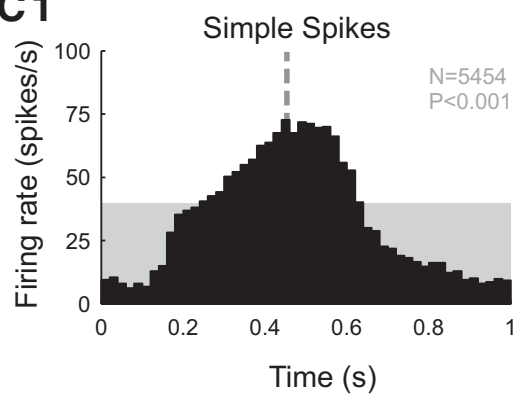

A2

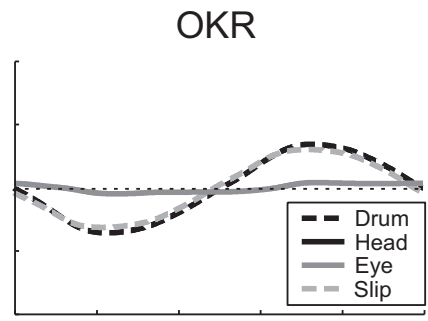

B2

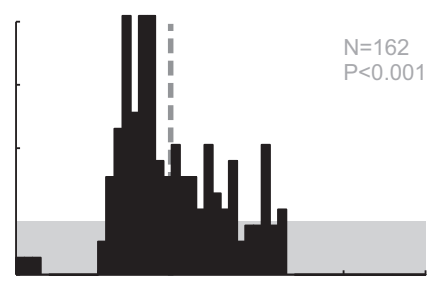

C2

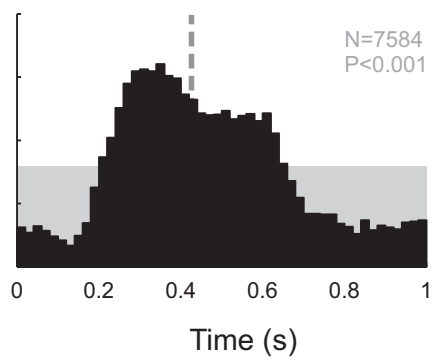

A3

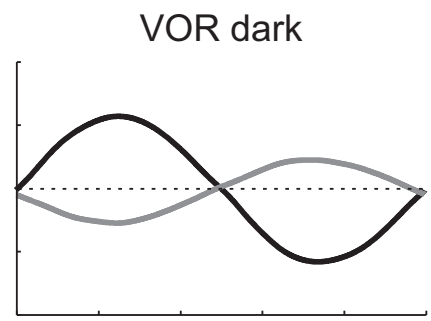

B3

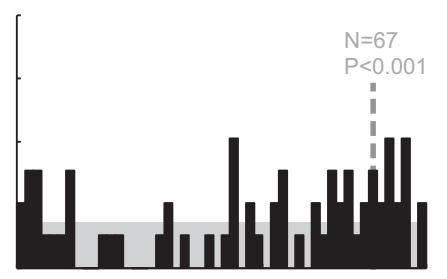

C3

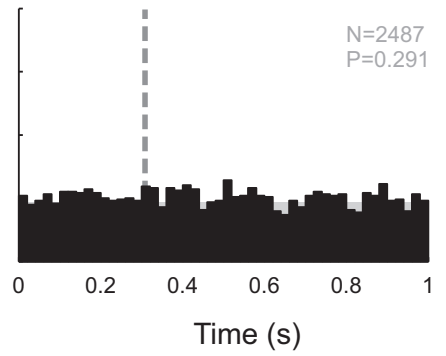

Figure 4. Histograms of single-unit activity of a cell representing a minority of floccular VA Purkinje cells for which the SSs fire in phase with the CSs. The cell was recorded during three different stimulus conditions as in Figure 3: vestibular stimulation in the light (column 1), optokinetic stimulation (column 2), and vestibular stimulation in the dark (column 3). The stimulus frequency was 1.0 Hz.A, Average angular velocity of the head (black line), the slow-phase eye movement (gray line), and the residual retinal image slip (light-gray dashed line). $\boldsymbol{B}$, Average CS firing rate. $\boldsymbol{C}$, Average simple spike firing rate. The amplitude of the optokinetic stimulus $\left(\boldsymbol{A}_{2}\right.$, black dashed line) was set to $3.5 \%$, so that the magnitude of the retinal image slip (light gray dashed line) approximately matched that of the slip during vestibular stimulation in the light $\left(A_{1}\right)$.

1999). We used Wilkie's approximation of the asymptotic distribution (Wilkie, 1983).

For the analysis of fast-phase saccadic eye movements during the vestibular nystagmus, fast-phase-triggered averages of CS activity were constructed over the $800 \mathrm{~ms}$ interval centered on the peak eye velocity. The distribution of CSs within this window was tested for (transient) deviation from the expected average firing rate using Kuiper's test (Kuiper, 1960). The expected average firing rate was computed for each fastphase-triggered average of a given stimulus condition by circular convolution of the total set of fast-phase occurrence times and CS occurrence times during slow-phase eye movements, both binned at $1 \mathrm{~ms}$ resolution and expressed as $\delta$-functions relative to the stimulus cycle.

Maximum likelihood model. To establish an unbiased estimate of the fraction of the population of recorded cells that shows CS modulation in the dark, one cannot rely on a simple count of cells with significant modulation. Rather than testing single cells, we chose to estimate the fraction of cells that modulate using the empirical distribution of modulation depth values. The probability of obtaining a certain modulation depth from a randomly sampled cell was modeled as a weighted sum of two probability density functions, one generated by unresponsive cells $\left(f_{0}\right)$ and the other generated by cells that are modulated with a given underlying modulation depth $\left(f_{1}\right)$.

CS firing was assumed to be stochastic (Keating and Thach, 1995) and sinusoidally modulated, so that the generative model of CS occurrences over the stimulus cycle corresponded to a cardioid distribution. The sampling distribution of modulation depth values was thus derived from the large-sample approximations of the sampling distribution of Rayleigh test values generated by the uniform and the cardioid distribution (Mardia and Jupp, 1999). The probability model fitted on the set of $m$ test scores $r \equiv\left\{r_{1}, \ldots, r_{m}\right\}$, had two free parameters: one being the fraction of modulating cells $a$ and the other being the underlying relative modulation depth $\rho$, and one fixed parameter $n$, indicating the number of CSs. We determined the parameter values $a$ and $\rho$ that had maximum likelihood using the function:

$$
\mathscr{L}(r \mid n, \rho, a)=\prod_{i=1}^{m}\left(a f_{1}\left(r_{i} \mid n_{i}, \rho\right)+(1-a) f_{0}\left(r_{i} \mid n_{i}\right)\right)
$$

Maximum likelihood estimates were made for the four stimulus combinations that were used as standard tests for CS modulation in the dark $\left(0.4 \mathrm{~Hz}\right.$ and $0.6 \mathrm{~Hz}$, both at $12.5^{\circ} / \mathrm{s}$ and $\left.25^{\circ} / \mathrm{s}\right)$ by computing the likelihood surface over the entire parameter space with a resolution of $0.1 \%$ for both parameters $\rho$ and $a$. Treating the modulation depth $\rho$ as a nuisance parameter, the profile likelihood functions of the modulation fraction parameter were combined to compute the fraction of modulating cells together with the $95 \%$ CI that best described all available test trials. A given combination of stimulus frequency and amplitude was regarded as a trial.

\section{Results}

\section{Basic characteristics of the nonvisual CS modulation}

We recorded CS activity during sinusoidal vestibular stimulation in the dark from VA floccular Purkinje cells in 10 rabbits. Data used for analysis were obtained from 467 cells, of which 300 were recorded from the Purkinje cell layer, indicated by the presence of both CSs and SSs, and 167 were recorded from the molecular 
A

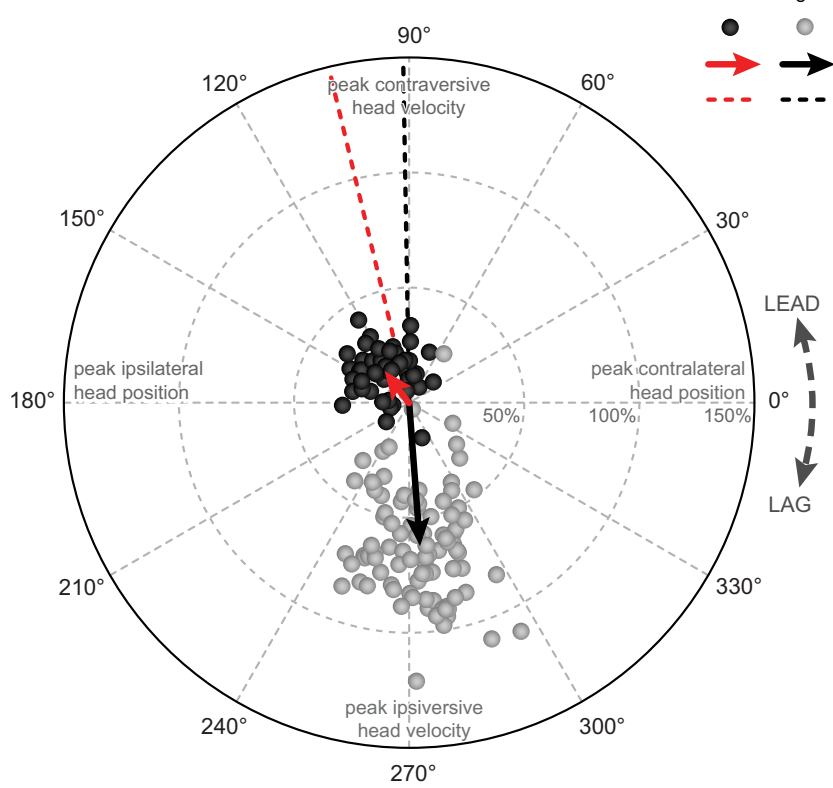

B

CS modulation single neuron

CS modulation average

Peak ipsiversive

eye velocity
$0.4 \mathrm{~Hz}$ at $12.5^{\circ} / \mathrm{s}$

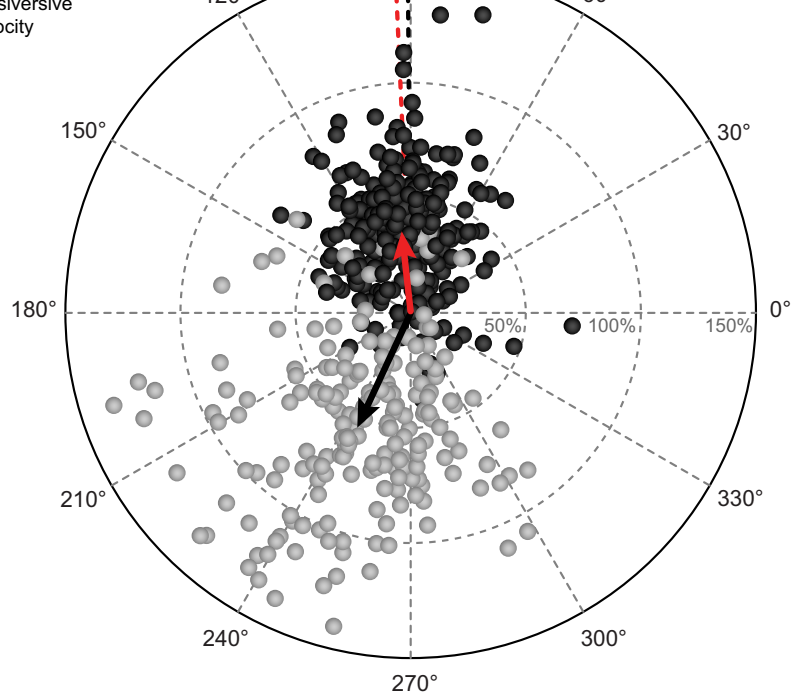

Figure 5. Comparison of the magnitude and phase angle distribution of the visual and nonvisual CS modulation. $A$, Results for all cells tested with vestibular stimulation at $0.1 \mathrm{~Hz}$ and $3.1 \% \mathrm{~s}$ peak velocity. $\boldsymbol{B}$, Results for all cells tested with vestibular stimulation at $0.4 \mathrm{~Hz}$ and $12.5^{\circ} / \mathrm{s}$ peak velocity. The polar plot magnitude corresponds to the amplitude of the $C S$ modulation relative to the average firing frequency. The phase of the CS modulation is relative to peak contralateral head position. Dark gray dots represent cells recorded during vestibular stimulation in the dark; light gray dots represent cells recorded during vestibular stimulation in the light. The arrows indicate the population mean (red for VOR in the dark, black for VOR in the light). Dashed lines indicate the average phase shift of the peak ipsiversive eye velocity relative to peak contralateral head position in the dark (red) and the light (black).

A

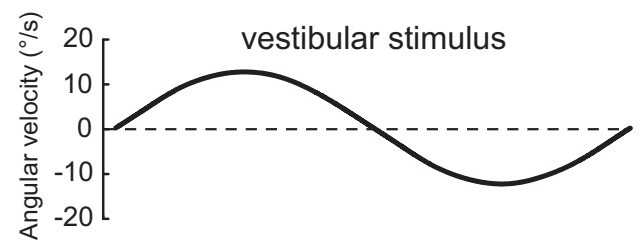

B

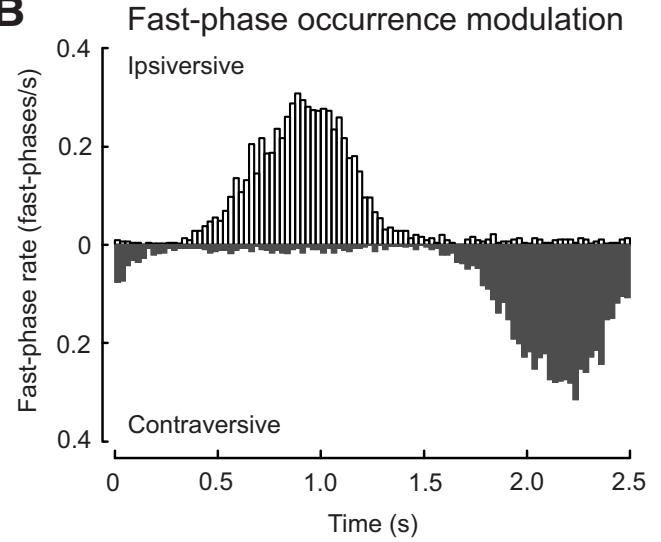

C1

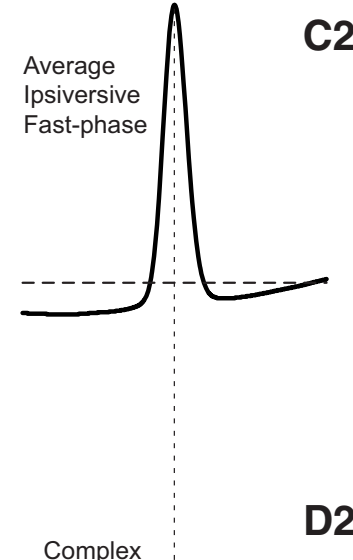

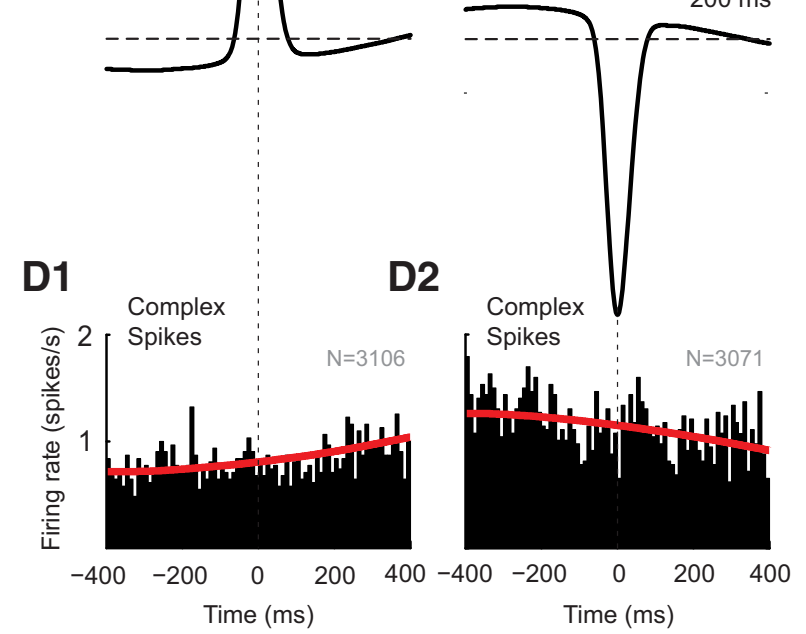

C2

Average

Contraversive

Fast-phase

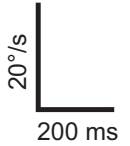

Figure 6. Absence of a relation between CS activity in the dark and the fast-phases of vestibular nystagmus. $\boldsymbol{A}$, Head velocity during one full $0.4 \mathrm{~Hz} z$ stimulus cycle with $12.5^{\circ} / \mathrm{stable} \mathrm{peak} \mathrm{velocity.} \boldsymbol{B}$, Histogram of the frequency distribution of fast-phase occurrences relative to the stimulus cycle $(0.4 \mathrm{~Hz}$ at $12.5 \%)$ for the cells illustrated in Figure $5 B$. Open bins represent ipsiversive fast-phases; gray bins represent contraversive fast-phases. C, Average of all ipsiversive (C1) and contraversive ( $(2)$ fast-phases from the VOR dark dataset presented in Figure 5B. Fast-phases were aligned on peak eye velocity. The averages include a portion of the slow-phase eye movement before and after the fast-phase. D, Average CS activity triggered on the peak velocity of either the ipsiversive (D1) or contraversive (D2) fast-phases shown in C1 and C2, respectively. N values indicate the number of fast-phases. Red lines indicate the fast-phase-triggered CS activity computed from the average CS modulation during slow-phase eye movement.

layer, with only CSs present. The average spontaneous CS firing frequency was 0.94 spikes/s for Purkinje cells with SSs recorded in the Purkinje cell layer and 1.03 spikes/s for Purkinje cells without SSs recorded in the molecular layer. A given combination of stim- ulus frequency and amplitude was regarded as a trial. For vestibular stimulation in the dark, a total of 1808 trials was obtained.

In complete darkness, the CS firing rate was frequently seen to be modulated in response to vestibular stimulation. The nonvi- 
$6.3 \% \mathrm{~s}$

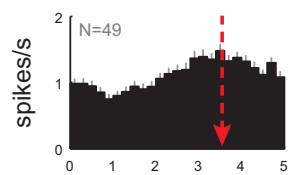

$0.4 \mathrm{~Hz}$

$0.6 \mathrm{~Hz}$

$0.8 \mathrm{~Hz}$

$1.0 \mathrm{~Hz}$
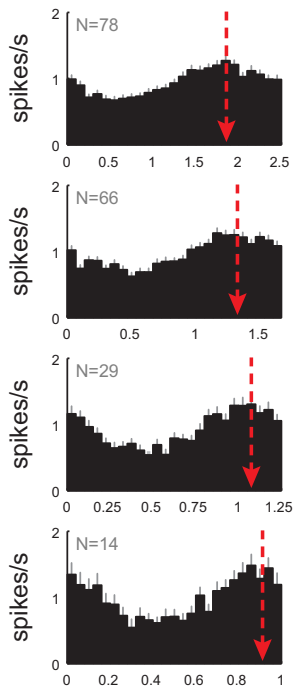

$1.2 \mathrm{~Hz}$

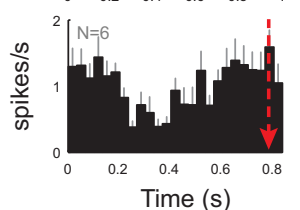

$12.5 \% \mathrm{~s}$
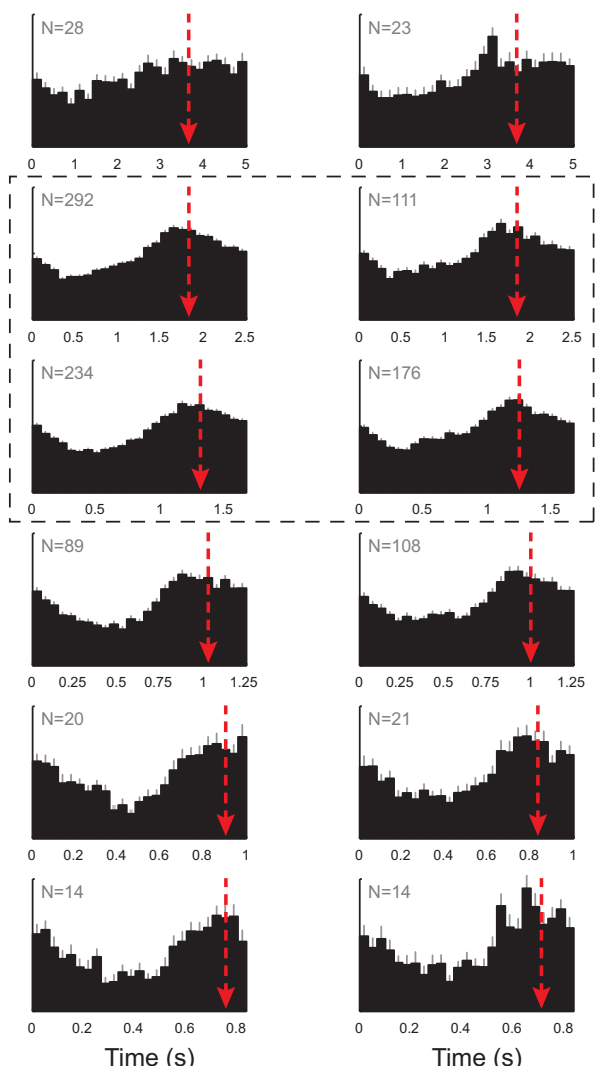

$25^{\circ} / \mathrm{s}$
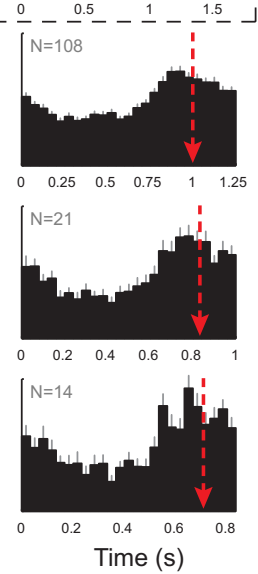

$37.5 \% \mathrm{~s}$
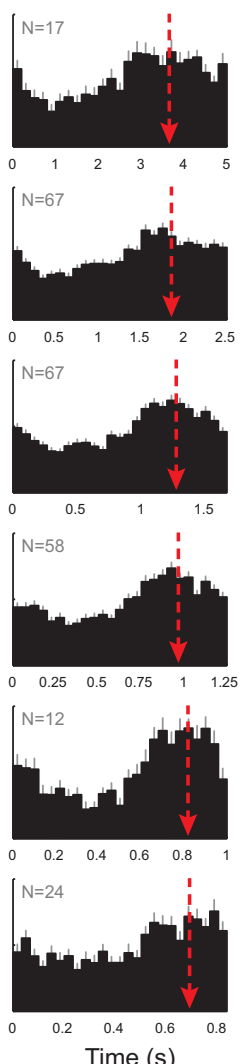

$50 \% \mathrm{~s}$
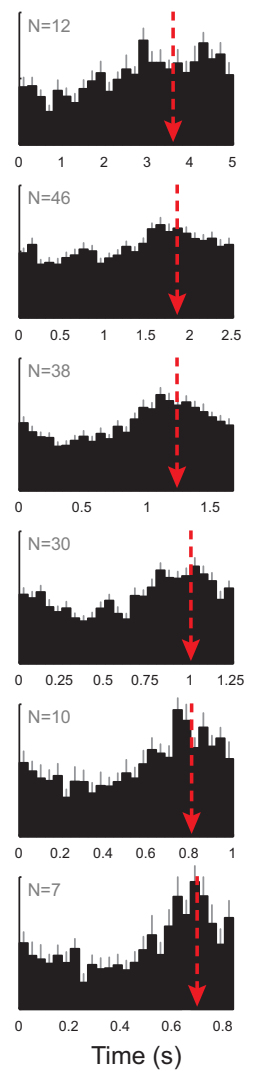

Figure 7. Stimulus frequency and amplitude dependence of the nonvisual CS modulation. The histograms represent the population average of the CS modulation for each tested combination of stimulus frequency and amplitude. The number of cells for each stimulus condition is given by $N$. The red arrows indicate the circular mean of the CS modulation and show the phase lead relative to peak contralateral head position. Error bars on each bin of the histograms indicate the SEM. Panels inside the dashed outline were used as standard conditions to test for nonvisual CS modulation.

sual CS modulation was better observed at higher than at lower stimulus velocities and frequencies. Figure 1 shows a representative example of the effect on CS modulation when the frequency and amplitude of the stimulus were increased from $0.1 \mathrm{~Hz}$ at $3.1 \%$ s (Fig. $1 A_{1}, A_{2}$ ) to $0.4 \mathrm{~Hz}$ at $12.5^{\circ} / \mathrm{s}$ (Fig. $1 A_{3}, A_{4}$ ). Both stimulus conditions produced a significant $(p<0.001)$ CS modulation in the light (Fig. $\left.1 B_{1}, B_{3}\right)$. On the other hand, CS modulation was absent in the dark at the lower frequency and amplitude condition (Fig. $1 B_{2}$ ), but the higher frequency and amplitude condition produced significant $(p<0.001)$ CS modulation in the dark $\left(\right.$ Fig. $\left.1 B_{4}\right)$ that was in phase with SS modulation, in contrast to the out-of-phase modulation in the light.

The distinctly different phase shift relative to head velocity of the vestibular-evoked CS response in the dark was a characteristic feature that set it apart from the modulation in the light. An example illustrating the difference between the CS modulation recorded in either the presence or absence of vision is shown in Figure 2. During VOR in the light with a stationary visual surround (Fig. 2, column 1), the CS firing rate of VA Purkinje cells typically increased with ipsiversive (nasal to temporal, with respect to the side of the recorded Purkinje cell) head movement and contraversive compensatory eye movement (Fig. $2 B_{1}$ ), whereas the SS firing rate (Fig. $2 C_{1}$ ) was usually approximately reciprocal (out of phase) to the CS firing rate. During optokinetic stimulation using a sinusoidally rotating drum (Fig. $2 \mathrm{~A}_{2}$ ), the CS modulation had a phase shift comparable to VOR in the light, which indicated that the modulation was mainly caused by the retinal image slip present in both conditions. This visual CS modulation is characteristic of floccular Purkinje cells (zone F1-F4) and has been well documented (Simpson and Alley, 1974; Graf et al., 1988; Kusunoki et al., 1990; Stone and Lisberger, 1990; Miura et al., 1993). During VOR in the dark, however, the phase of the CS modulation (Fig. $2 B_{3}$ ) became opposite to that during the modulation in the light (Fig. $2 B_{1}$ ), such that the CS firing rate increased with contraversive (temporal to nasal) head movement. Because the phase of the SS modulation did not change, the CS modulation during VOR in the dark was in phase with the SS modulation (Fig. 2 $C_{3}$ ).

Another stimulus condition in which the CS activity increases with contraversive head movement, but in the presence of vision, is VOR cancellation. An example comparing VOR cancellation with VOR in the light and the dark is depicted in Figure 3. During VOR cancellation (Fig. 3, column 2 ), the visual surround, created by the optokinetic drum (Fig. $3 \mathrm{~A}_{2}$; red dashed line), moved in phase with the head, so that the VOR should be suppressed to retain stable vision. Because cancellation of the VOR is suboptimal, retinal image slip present in this condition moves together with the vestibular stimulus, which is opposite to that during normal VOR in the light (Fig. $3 A_{1}$ ). Although the CS modulation during both VOR cancellation (Fig. $3 B_{2}$ ) and VOR in the dark (Fig. $3 B_{3}$ ) is opposite to VOR in the light (Fig. $3 B_{1}$ ), the SS modulation reversed as well during VOR cancellation (Fig. $3 C_{2}$ ), but not during VOR in the dark (Fig. $3 C_{3}$ ), producing in-phase firing of CSs and SSs in the latter condition.

Of the 300 cells for which both CS and SS were recorded in the Purkinje cell layer, 185 cells were additionally tested with VOR 

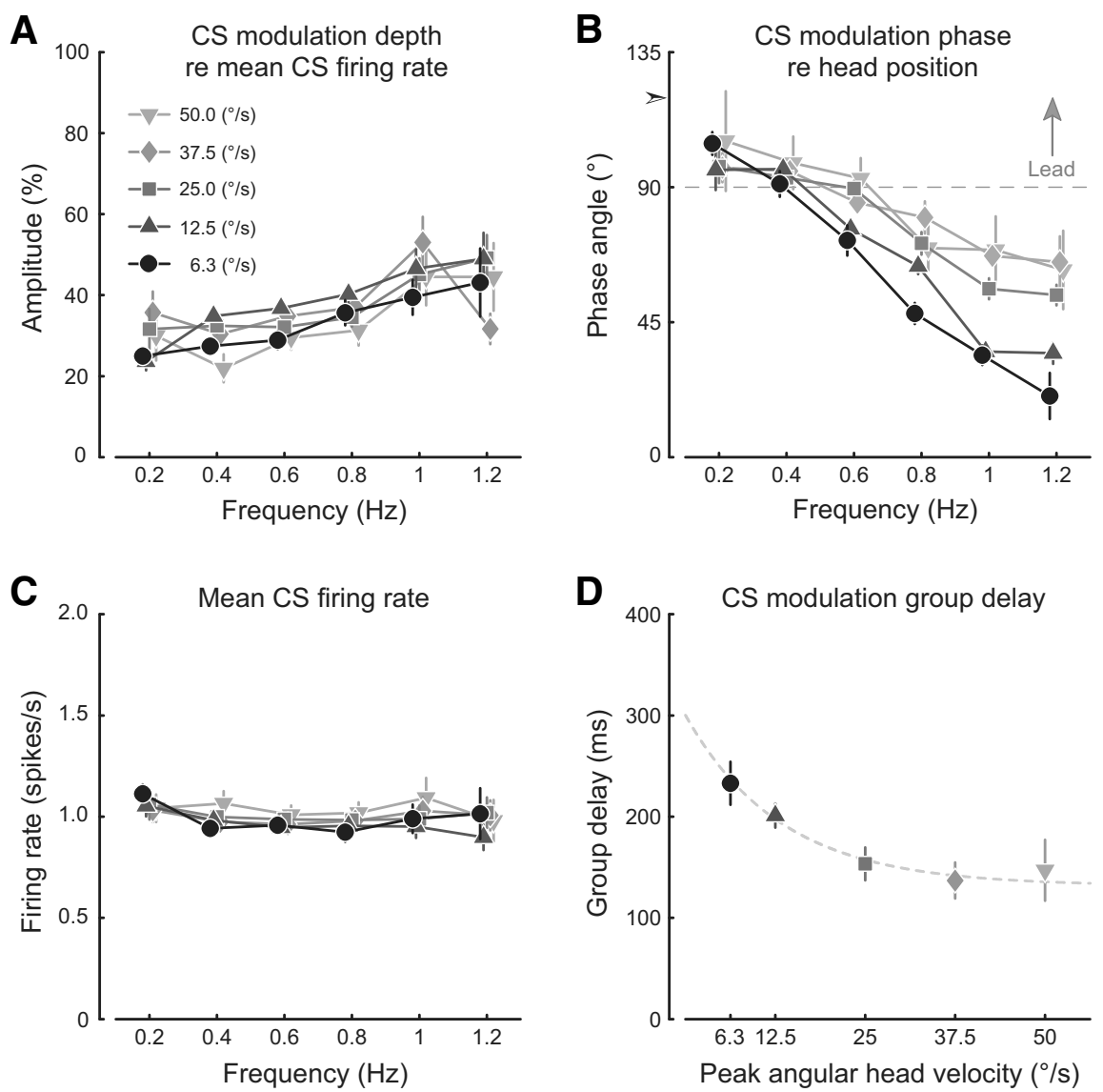

Figure 8. Graphic summary of the stimulus frequency and amplitude dependence of the nonvisual CS modulation. $\boldsymbol{A}$, The dependence of the average $C S$ modulation amplitude on stimulus frequency with stimulus peak velocity as the parameter. $\boldsymbol{B}$, The dependence of the average CS modulation phase angle on stimulus frequency with stimulus peak velocity as the parameter. The common intercept with the ordinate at $0 \mathrm{~Hz}$ is indicated by the arrowhead at a phase angle of $120^{\circ}$. Phase angles are relative to peak contralateral head position. The dashed gray reference line indicates peak contraversive head velocity. $\boldsymbol{C}$, The dependence of the average CS firing rate on stimulus frequency with stimulus peak velocity as the parameter. D, Group delay of the CS modulation for each stimulus velocity. The dashed gray line is a least-squares exponential function fit. Error bars indicate $95 \% \mathrm{Cl}$. $\boldsymbol{A}-\boldsymbol{C}$, The stimulus velocity profiles are presented with small offsets relative to each other along the abscissa to avoid overlapping error bars.

stimulation in the light. The great majority (163 of 185) of these Purkinje cells showed SS modulation that was approximately out of phase with CS modulation during VOR in the light and in phase during VOR in the dark. However, in a small number of cells (5 of 185), the SS modulation during VOR in the light increased with ipsiversive head movement, such that it was in phase with CS modulation. An example of such a cell is provided in Figure 4 and shows strong in-phase activity of CSs and SSs during the VOR in the light (Fig. 4, column 1) and OKR (Fig. 4, column 2). Of interest is the fact that, during VOR in the dark, the SSs are not modulated (Fig. $4 C_{3}$ ), although the CSs are modulated (Fig. $4 B_{3}$ ) with the same phase angle relative to the stimulus as in the previous figures. Furthermore, the absence of SS modulation in the dark stands in contrast to the strong SS modulation during OKR and VOR in the light, suggesting that the SS modulation for this cell is caused by visual input only.

Those Purkinje cells whose optimal visual CS response axes were aligned with the horizontal plane at approximately ipsilateral $135^{\circ}$ or contralateral $45^{\circ}$ azimuth (HA cells) were occasionally tested for nonvisual modulation with the same VA stimuli used to test VA cells. A set of 149 trials from 72 HA Purkinje cells was recorded, of which 55 were recorded in the Purkinje cell layer and 17 in the molecular layer. Only a small fraction of these HA cells showed significant CS modulation $(p<0.01$, data not shown) to vestibular stimulation in the dark at the standard frequency/amplitude combinations that were effective for most VA cells ( 4 of 33 at $0.4 \mathrm{~Hz}$ and 2 of 35 at 0.6 $\mathrm{Hz}$, both at $12.5^{\circ}$ s stimulus peak velocity). We noted, however, that most cells stimulated at the high end of the frequency/amplitude range showed significant CS modulation (e.g., 5 of 7 at $1.2 \mathrm{~Hz}$ at $37.5^{\circ}$ \% $\mathrm{s})$. Activation of the posterior and anterior semicircular canals, whose activation axes are not fully orthogonal to the stimulus axis, most likely explains the response in HA cells.

\section{Population response}

The example presented in Figure 1 suggests a dependence of CS modulation in the dark on stimulus frequency and velocity. This dependence is shown in the polar plots of Figure 5 for all recorded Purkinje cells for which stimulus conditions corresponded to those shown for the example cell in Figure 1. At low frequency and amplitude of stimulation (Fig. $5 A, 0.1 \mathrm{~Hz}$ and $3.1 \%$ ) almost none of the cells, tested on an individual basis, showed significant CS modulation during VOR in the dark ( 1 of $48, p<0.01$, Rayleigh test). A tendency to modulate is, however, observable in the population distribution because it is not centered at the origin. The population average (Fig. 5A, red arrow) has a distinct magnitude and phase angle that is leading contraversive head velocity by $\sim 30^{\circ}$ and approximately in phase with ipsiversive eye velocity (red dashed line). Therefore, CS modulation was present in at least a fraction of the population, but the modulation amplitude fell below the detection level given the number of CSs recorded for individual cells. During VOR in the light, the CS modulation was significant for the majority of PCs $(81$ of $96, p<0.01)$ and on average (Fig. 5A, black arrow) in phase with ipsiversive head velocity and contraversive eye velocity.

When the stimulus frequency and velocity were increased (Fig. $5 B, 0.4 \mathrm{~Hz}$ at $12.5^{\circ} / \mathrm{s}$ ) approximately half the cells showed significant CS modulation during VOR in the dark (142 of 292, $p<0.01$, Rayleigh test). The magnitude of the population average increased substantially and remained close to in phase with ipsilateral eye velocity (Fig. 5B, red arrow). CS modulation during VOR in the light was significant for most cells (145 of 193, $p<$ 0.01 ), showing on average (Fig. $5 B$, black arrow) no difference in magnitude compared with the results at low stimulus frequency/ velocity. A substantial phase lag was present relative to ipsilateral head velocity and contralateral eye velocity.

\section{Fast-phase of vestibular nystagmus}

At certain combinations of stimulus frequency and amplitude rabbits respond with compensatory eye movements composed of 
both slow and fast-phases of vestibular nystagmus. Ipsiversive and contraversive fast-phases tended to occur at specific times within the stimulus cycle. Figure 6 illustrates the modulation of fast-phase occurrences (Fig. $6 B$ ) during the stimulus cycle (Fig. $6 A)$ at $0.4 \mathrm{~Hz}$ and $12.5 \%$. The rate of fast-phase occurrences increases with the position amplitude of the vestibular stimulus. To analyze CS activity over a wide range of stimulus frequencies and amplitudes, we looked for a possible relation between CS activity and the fast-phase of nystagmus. We made fast-phasetriggered averages of CS activity, using peak velocity as the trigger, to reveal possible transient changes in CS activity that are fast-phase dependent. As shown in Figure 6 for both ipsiversive (Fig. $6 C 1, D 1$ ) and contraversive fast-phases (Fig. 6C2,D2) at 0.4 $\mathrm{Hz}$ and $12.5 \%$, no relationship was seen. The absence of a relationship was found throughout the tested stimulus range of $0.2-$ $1.2 \mathrm{~Hz}$ and $6.3-50^{\circ} \%$ s. For all stimulus conditions that contained a minimum of 100 fast-phases, the distribution of CSs over the 800 ms interval centered on the fast-phases was statistically compared with the expected distribution of CSs computed from the average CS modulation during slow-phase eye movement. Of the 44 tested conditions ( 24 for ipsiversive and 20 for contraversive fastphases), 42 conditions showed no significantly different CS distribution at the $p<0.01$ level, and none of the conditions was significant after Bonferroni correction.

\section{Statistical estimation of the population size of cells with nonvisual CS modulation}

As presented in Materials and Methods, a simple count of cells with significant CS modulation in the dark does not produce a reliable estimate of the fraction of modulating cells. We therefore estimated this number from the empirical distribution of relative modulation depth values, by fitting a generative model composed of a mixture of two distributions: one describing the fraction of nonmodulating cells and the other describing the fraction of cells modulating sinusoidally with a given modulation amplitude that was assumed constant for each stimulus frequency/velocity combination. The two model parameters, the fraction of modulated cells and the modulation amplitude, which described the observed data distribution with maximum likelihood, were computed for the four stimulus combinations $(0.4$ and $0.6 \mathrm{~Hz}$, both at $12.5 \%$ and $25 \%$ s) that served to systematically test cells for nonvisual CS modulation. The fraction of dark modulating cells estimated from the combined profile likelihood functions of these stimulus conditions was $78.3 \%$ (95\% CI, 73.1-83.3\%). Because the average modulation depth of a cell population that includes nonmodulating cells underestimates the modulation depth of the subpopulation of modulating cells, the maximum likelihood estimates of the relative modulation depth was calculated using the estimated percentage of modulating cells as a fixed parameter. For each of the four stimulus conditions, the average relative modulation depths and CIs were as follows: $43.6 \%$ (CI, 41.9$46.1 \%$ ) for $0.4 \mathrm{~Hz}$ at $12.5^{\circ} \mathrm{s}, 42 \%$ (CI, 39.1-48.1\%) for $0.4 \mathrm{~Hz}$ at $25 \%, 47.4 \%$ (CI, $43.3-47.7 \%$ ) for $0.6 \mathrm{~Hz}$ at $12.5^{\circ} / \mathrm{s}$, and $42.6 \%$ (CI, $40.7-46.9 \%$ ) for $0.6 \mathrm{~Hz}$ at $25 \%$ s.

\section{Frequency and velocity dependence}

To form a more complete picture of the signals carried by floccular climbing fibers, we quantified the nonvisual CS modulation over the frequency range of $0.2-1.2 \mathrm{~Hz}$ in combination with the velocity range of $6.3-50.0 \%$. Although not all cells could be tested for each of these 30 frequency/velocity combinations, representative cells were available for each combination within the indicated range.

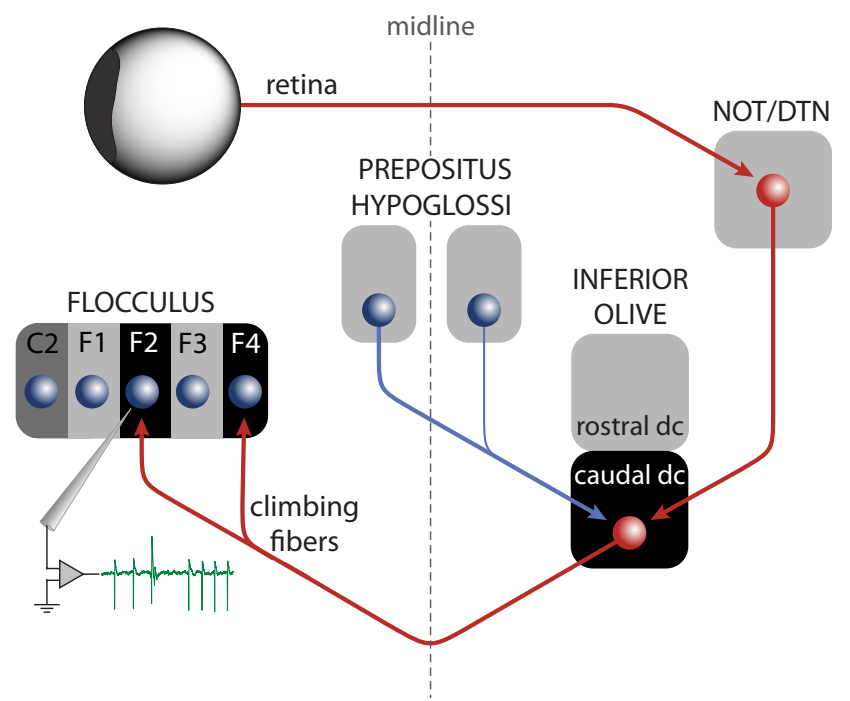

Figure 9. Schematic drawing of the input and output relations of the caudal dorsal cap of the inferior olive. The excitatory pathway (red arrows) relays the retinal slip signal via the accessory optic system to the climbing fibers that project to the VA zones (F2 and F4) of the flocculus. Recording from one of these zones is indicated by the green trace, which shows an example of SSs and a CS. The inhibitory projection from the PrH to the caudal dorsal cap (blue arrow) is the proposed source of the nonvisual signals carried by the floccular climbing fibers.

To determine the properties of the nonvisual signal carried by the climbing fiber population, the mean CS modulation was calculated for all cells recorded at each tested stimulus combination, as depicted in Figure 7. The CS modulation becomes essentially sinusoidal as the number of cells increases. In contrast, sinusoidal optokinetic stimulation typically produces nonsinusoidal CS modulation (e.g., Fig. $2 \mathrm{~B}_{2}$ ) because of the highly nonlinear tuning to retinal slip velocity (Simpson and Alley, 1974; Barmack and Hess, 1980; Kusunoki et al., 1990). The sinusoidal shape of the average nonvisual CS modulation suggests a more linear relation with the sinusoidal input signal. When the frequency was increased, but with peak stimulus velocity held constant (Fig. 7, each column), the phase angle of the average CS modulation (red arrow) systematically moved from close to peak contraversive head velocity toward contralateral head position.

The results depicted in Figure 7 are summarized graphically in Figure 8. The average value for all recorded cells is calculated, including nonmodulating cells. The modulation amplitude (Fig. $8 A$ ) increased modestly with frequency (from $\sim 0.3$ spikes $/ \mathrm{s}$ at 0.2 $\mathrm{Hz}$ to 0.4 spikes/s at $1.2 \mathrm{~Hz}$, averaged over stimulus amplitudes), whereas the average $\mathrm{CS}$ firing rate (Fig. $8 \mathrm{C}$ ) remained essentially unchanged from the canonical spontaneous value of $1 \mathrm{~Hz}$ in all stimulus conditions. On the other hand, stimulus frequency had a large effect on the phase response of the CS modulation relative to peak contralateral head position (Fig. $8 B$ ). While the phase of the eye movement itself remained close to peak contraversive head velocity, leading head velocity on average by no more than $10^{\circ}$ (at $0.6 \mathrm{~Hz}$ and $6.3^{\circ} \%$ ) and showing a maximal average phase lag of no more than $3^{\circ}$ (at $1.2 \mathrm{~Hz}$ and $50.0^{\circ} / \mathrm{s}$ ), the phase response of the CS modulation declined substantially (toward an increase in phase lag) from being close to in phase with contraversive head velocity at the low end of the frequency range, shifting toward contralateral head position at the high end of the frequency range. The rather linear increase in phase lag indicated that all frequency components of the stimulus were delayed approximately equally in the CS response. An estimate of the group delay was computed from the slopes of the phase response by fitting a 


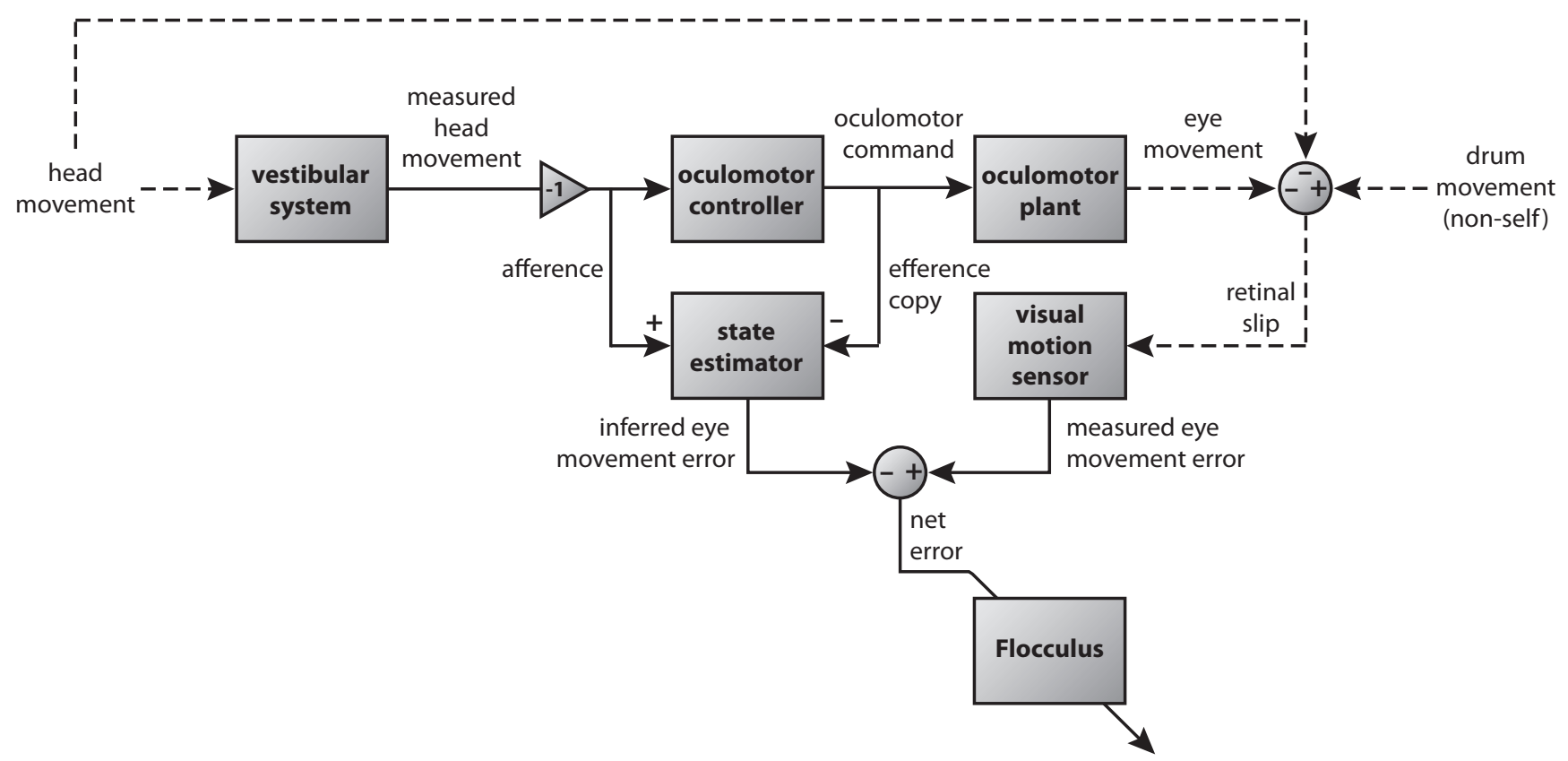

Figure 10. Functional block diagram showing the sources of error signals that contribute to the climbing fiber signal to the flocculus. The state estimator is suggested to be the nuclei prepositus hypoglossi in which afferent vestibular signals are compared with efferent copy eye movement signals to produce an inferred eye movement error signal. The modulation depth of the combination of these two signals, presumed to occur in the nuclei prepositus hypoglossi, is the measure of the inferred error. The nonlinearity of this signal precludes a straightforward prediction of the changes in its modulation depth when its two components, which have opposite polarities, change. The inferred error is sent as an inhibitory input to the inferior olive where it is combined with an excitatory input from the accessory optic system signaling retinal slip, producing a net error signal sent to the flocculus.

linear function, revealing an asymptotic decrease in the group delay with increasing stimulus velocity (Fig. 8D). Remarkably, the increase in phase lag (Fig. $8 B$ ) with frequency was substantially greater at low stimulus peak velocities than at high stimulus peak velocities. Such a velocity dependence of the phase response indicates that the phase changes are not due to only a fixed delay, but rather also reflect a system nonlinearity.

\section{Discussion}

More than three-fourths of the floccular Purkinje cells whose CSs respond to contraversive retinal image slip also exhibit CS modulation without vision when the rabbit is passively rotated in the dark. The visual and nonvisual CS modulations are, respectively, out of phase and in phase with contraversive head velocity. Because for most cells the phase of the SS modulation does not change appreciably between light and dark, the CS modulation shifts from being out of phase to being in phase with the concomitant SS activity. These findings show that CS-SS "reciprocity" is not universal (e.g., see Yakusheva et al., 2010), not even in the flocculus for which reciprocity is often a centerpiece in presenting cerebellar function.

The visual CS modulation is readily associated with a performance error (Ito, 1982; Graf et al., 1988), but it is less obvious how the nonvisual signal should be interpreted. The phase response of the nonvisual modulation indicated that it was mostly a velocity signal. However, the modulation could not be attributed to either head or eye velocity alone, as the modulation depth showed remarkably little change with increasing stimulus peak velocity.

Previous studies have shown that the eye movement context influences the representation of retinal slip by the climbing fibers (CFs) (Kobayashi et al., 1998; Frens et al., 2001; Winkelman and Frens, 2006; Ke et al., 2009). During optokinetic stimulation with the head stationary, the CS activity of VA Purkinje cells increased specifically when contraversive retinal slip coincided with contraversive eye movement (Winkelman and Frens, 2006). In contrast, the present study showed an increase in CS activity with head movement in the dark into the contralateral direction while the eye moved into the ipsilateral direction. The difference from the results obtained when the head was stationary suggests that CS modulation in the dark consists of two directionally opposing signals: one related to head movement and another related to eye movement.

During VOR in darkness, with the head and eye moving in opposite directions, the net modulation was dominated by the vestibular signal. The combination of these two opposing signals reflects gaze change and can be viewed as an estimate of eye movement error related to self-movement, inferred by the brain from nonvisual sources. Retinal slip can be considered the actual eye movement error signal, measured directly at the retina. We hypothesize that, during VOR in light, both the retinal slip and the inferred eye movement error signals coalesce in floccular CS activity, although the amplitude and phase of the nonvisual signal may differ from the observed CS modulation in darkness because VOR eye movement gain is generally higher with vision.

\section{Anatomical relations}

The great majority of floccular CFs originate in the dorsal cap (DC) of Kooy and the adjacent ventrolateral outgrowth of the contralateral inferior olive (IO) (Alley et al., 1975; Leonard et al., 1988; Kusunoki et al., 1990; Tan et al., 1995). The CFs that signal retinal slip for VA rotation arise from the caudal half of the DC and project to Purkinje cells in two distinct floccular zones (F2 and F4) related to VA eye movements (De Zeeuw et al., 1994; Van der Steen et al., 1994). These Purkinje cells were sampled in the present study as indicated in the anatomical diagram in Figure 9. The caudal DC receives excitatory and inhibitory input from two distinct sources. The excitatory projection, carrying visual sig- 
nals, arises from the nucleus of the optic tract (NOT) and the dorsal terminal nucleus (DTN) of the accessory optic system (AOS) (Mizuno et al., 1974; Hoffmann et al., 1976; Takeda and Maekawa, 1976; Giolli et al., 1988; Simpson et al., 1988; Mustari et al., 1994). The inhibitory input consists of a major contralateral projection and a minor ipsilateral projection from a population of relatively small cells in the nucleus prepositus hypoglossi $(\mathrm{PrH})$ that do not send axon collaterals to the oculomotor nuclei (Gerrits et al., 1985; McCrea and Baker, 1985; Barmack et al., 1993; De Zeeuw et al., 1993; Wentzel et al., 1995). Bilateral ablative lesions of the PrH increased baseline floccular CS activity without a significant influence on optokinetically elicited CS modulation in anesthetized rabbits (Arts et al., 2000). The projection from the PrH is the most likely source of the nonvisual CF signal because recordings from PrH cells show that they carry a variety of vestibular and oculomotor signals (Delgado-García et al., 1989; Escudero et al., 1992; Escudero et al., 1996), including those that report the difference between eye and head velocity (McFarland and Fuchs, 1992).

The possibility that the nonvisual CS signal originates in the AOS is unlikely because, without vision, modulation of neuronal activity in the NOT/DTN has not been observed during either vestibular stimulation (Mustari and Fuchs, 1990) or slow-phase optokinetic after-nystagmus (Ilg and Hoffmann, 1996). However, transient inhibition of NOT activity has been shown to occur after saccadic eye movements in a small number of NOT neurons (Mustari and Fuchs, 1990; Ilg and Hoffmann, 1996). Whether any of these neurons projects to the IO is not known. In our studies, we could not identify an effect of nystagmic fastphases on CS activity (Fig. 6).

The inhibition from the PrH to the caudal DC may serve a role analogous to the inhibition from the cerebellar nuclei to the other parts of the IO and which has been implicated in the extinction of learned behaviors (Medina et al., 2002; Cohen et al., 2004), such as the conditioned response to a tone in eye blink conditioning experiments. Somatosensory signals induced by the unconditioned stimulus are inhibited at the IO once an association with the conditioned stimulus had been developed (Sears and Steinmetz, 1991). The signal inhibiting CS activity is driven at least partly by cerebellar output, which in the present case appears to be an inferred eye movement error signal coming from the PrH. In this context of reducing SS activity, we note that the nonvisual modulation is approximately in phase with the SS modulation, in contrast to the relation that exists in the light. Moreover, behavioral studies indicate that nonvisual error signals contribute to VOR adaptation in addition to the visual error represented by retinal slip (Shelhamer et al., 1994).

\section{Error signals}

Following Oscarsson's comparator proposal (Oscarsson, 1980), most investigators have regarded CS modulation as an error signal that contributes to motor adaptation through induction of cerebellar synaptic plasticity (Raymond et al., 1996; Simpson et al., 1996; Broussard and Kassardjian, 2004; Ito, 2013). If so, the nature of the error signals is fundamentally related to the neural representation developed in the cerebellar cortex (Wolpert and Miall, 1996). With regard to modeling floccular control of eye movement adaptation, retinal slip has usually been considered to be the exclusive source of error (Ito, 1972, 1982; Robinson, 1976; Fujita, 1982; Kawato and Gomi, 1992; Quinn et al., 1992; Dean et al., 2002; Tabata et al., 2002; Hirata et al., 2003). To achieve stable vision, retinal slip needs to be minimized. Because a change in eye velocity induces a change in retinal slip that is equal in magni- tude, the latter has therefore been classically interpreted as equivalent to an error in motor execution or the motor command. Motor error would be appropriate for training a structure directly involved in motor control, such as an inverse model of the oculomotor plant (Shidara et al., 1993; Wolpert et al., 1998). The classification of CS modulation as a motor error signal has, however, been questioned, for example, in relation to saccade modification (Catz et al., 2005; but see Soetedjo and Fuchs, 2006), and in relation to reaching (Gibson et al., 2004). The comparator proposal is captured by our proposition that the retinal slip signals from the AOS are combined with vestibular-ocular signals from the $\mathrm{PrH}$ at the IO.

The presence of two distinguishable eye movement error signals, one measuring the actual sensory feedback (retinal slip) and the other an inferred eye movement error signal, requires that the role of CFs in models of floccular control of eye movement adaptation be expanded beyond retinal slip, which has consequences for the general interpretation of floccular function. A block diagram showing the proposed composition of the CF signals to the flocculus is laid out in Figure 10. The nonvisual error signal that competes with the retinal slip signal at the IO shows a group delay that approaches the retinal slip delay of $\sim 100 \mathrm{~ms}$ (Stone and Lisberger, 1990). This timing relation may act to moderate the effect of time delays inherent in feedback control systems (Miall et al., 1993). The combination of these two error signals in the IO results in a net error signal, conveyed by the floccular CFs and reporting the discrepancy between actual and inferred sensory feedback (Darlot, 1993; Winkelman and Frens, 2006). This signal is appropriate for training a structure involved in sensory state estimation by means of a forward model (Wolpert and Miall, 1996). Manipulation of the inferred error signal could be tested in future experiments by measuring the nonvisual CS modulation during VOR adaptation training, which rescales the eye movement response to vestibular stimulation.

\section{References}

Albus JS (1971) A theory of cerebellar function. Math Biosci 10:25-61. CrossRef

Alley K, Baker R, Simpson JI (1975) Afferents to the vestibulo-cerebellum and the origin of the visual climbing fibers in the rabbit. Brain Res 98:582589. CrossRef Medline

Arts MP, De Zeeuw CI, Lips J, Rosbak E, Simpson JI (2000) Effects of nucleus prepositus hypoglossi lesions on visual climbing fiber activity in the rabbit flocculus. J Neurophysiol 84:2552-2563. Medline

Barmack NH, Hess DT (1980) Multiple-unit activity evoked in dorsal cap of inferior olive of the rabbit by visual stimulation. J Neurophysiol 43:151164. Medline

Barmack NH, Fagerson M, Errico P (1993) Cholinergic projection to the dorsal cap of the inferior olive of the rat, rabbit, and monkey. J Comp Neurol 328:263-281. CrossRef Medline

Blanks RH, Precht W (1983) Responses of units in the rat cerebellar flocculus during optokinetic and vestibular stimulation. Exp Brain Res 53:1-15. Medline

Broussard DM, Kassardjian CD (2004) Learning in a simple motor system. Learn Mem 11:127-136. CrossRef Medline

Catz N, Dicke PW, Thier P (2005) Cerebellar complex spike firing is suitable to induce as well as to stabilize motor learning. Curr Biol 15:2179-2189. CrossRef Medline

Cohen MR, Meissner GW, Schafer RJ, Raymond JL (2004) Reversal of motor learning in the vestibulo-ocular reflex in the absence of visual input. Learn Mem 11:559-565. CrossRef Medline

Darlot C (1993) The cerebellum as a predictor of neural messages: I. The stable estimator hypothesis. Neuroscience 56:617-646. CrossRef Medline

Dean P, Porrill J, Stone JV (2002) Decorrelation control by the cerebellum achieves oculomotor plant compensation in simulated vestibulo-ocular reflex. Proc Biol Sci 269:1895-1904. CrossRef Medline

Delgado-García JM, Vidal PP, Gómez C, Berthoz A (1989) A neurophysio- 
logical study of prepositus hypoglossi neurons projecting to oculomotor and preoculomotor nuclei in the alert cat. Neuroscience 29:291-307. CrossRef Medline

De Zeeuw CI, Wentzel P, Mugnaini E (1993) Fine structure of the dorsal cap of the inferior olive and its GABAergic and non-GABAergic input from the nucleus prepositus hypoglossi in rat and rabbit. J Comp Neurol 327: 63-82. CrossRef Medline

De Zeeuw CI, Wylie DR, DiGiorgi PL, Simpson JI (1994) Projections of individual Purkinje cells of identified zones in the flocculus to the vestibular and cerebellar nuclei in the rabbit. J Comp Neurol 349:428-447. CrossRef Medline

De Zeeuw CI, Wylie DR, Stahl JS, Simpson JI (1995) Phase relations of Purkinje cells in the rabbit flocculus during compensatory eye movements. J Neurophysiol 74:2051-2064. Medline

Eccles JC, Llinás R, Sasaki K (1966) The excitatory synaptic action of climbing fibres on the Purinje cells of the cerebellum. J Physiol 182:268-296. Medline

Escudero M, de la Cruz RR, Delgado-García JM (1992) A physiological study of vestibular and prepositus hypoglossi neurones projecting to the abducens nucleus in the alert cat. J Physiol 458:539-560. Medline

Escudero M, Cheron G, Godaux E (1996) Discharge properties of brain stem neurons projecting to the flocculus in the alert cat: II. Prepositus hypoglossal nucleus. J Neurophysiol 76:1775-1785. Medline

Frens MA, Mathoera AL, van der Steen J (2001) Floccular complex spike response to transparent retinal slip. Neuron 30:795-801. CrossRef Medline

Fujita M (1982) Simulation of adaptive modification of the vestibulo-ocular reflex with an adaptive filter model of the cerebellum. Biol Cybern 45: 207-214. CrossRef Medline

Gerrits NM, Voogd J, Magras IN (1985) Vestibular afferents of the inferior olive and the vestibulo-olivo-cerebellar climbing fiber pathway to the flocculus in the cat. Brain Res 332:325-336. CrossRef Medline

Ghelarducci B, Ito M, Yagi N (1975) Impulse discharges from flocculus Purkinje cells of alert rabbits during visual stimulation combined with horizontal head rotation. Brain Res 87:66-72. CrossRef Medline

Gibson AR, Horn KM, Pong M (2004) Activation of climbing fibers. Cerebellum 3:212-221. CrossRef Medline

Giolli RA, Torigoe Y, Blanks RH, McDonald HM (1988) Projections of the dorsal and lateral terminal accessory optic nuclei and of the interstitial nucleus of the superior fasciculus (posterior fibers) in the rabbit and rat. J Comp Neurol 277:608-620. CrossRef Medline

Goldberg JM, Brown PB (1969) Response of binaural neurons of dog superior olivary complex to dichotic tonal stimuli: some physiological mechanisms of sound localization. J Neurophysiol 32:613-636. Medline

Graf W, Simpson JI, Leonard CS (1988) Spatial organization of visual messages of the rabbit's cerebellar flocculus: II. Complex and simple spike responses of Purkinje cells. J Neurophysiol 60:2091-2121. Medline

Granit R, Phillips CG (1956) Excitatory and inhibitory processes acting upon individual Purkinje cells of the cerebellum in cats. J Physiol 133: 520-547. Medline

Hirata Y, Takeuchi I, Highstein SM (2003) A dynamical model for the vertical vestibuloocular reflex and optokinetic response in primate. Neurocomputing 52:531-540. Medline

Hoffmann KP, Behrend K, Schoppmann A (1976) A direct afferent visual pathway from the nucleus of the optic tract to the inferior olive in the cat. Brain Res 115:150-153. CrossRef Medline

Ilg UJ, Hoffmann KP (1996) Responses of neurons of the nucleus of the optic tract and the dorsal terminal nucleus of the accessory optic tract in the awake monkey. Eur J Neurosci 8:92-105. CrossRef Medline

Ito M (1972) Neural design of the cerebellar motor control system. Brain Res 40:81-84. CrossRef Medline

Ito M (1982) Cerebellar control of the vestibulo-ocular reflex: around the flocculus hypothesis. Annu Rev Neurosci 5:275-296. CrossRef Medline

Ito M (2013) Error detection and representation in the olivo-cerebellar system. Front Neural Circuits 7:1. CrossRef Medline

Judge SJ, Richmond BJ, Chu FC (1980) Implantation of magnetic search coils for measurement of eye position: an improved method. Vision Res 20:535-538. CrossRef Medline

Kawato M, Gomi H (1992) The cerebellum and VOR/OKR learning models. Trends Neurosci 15:445-453. CrossRef Medline

Ke MC, Guo CC, Raymond JL (2009) Elimination of climbing fiber instruc- tive signals during motor learning. Nat Neurosci 12:1171-1179. CrossRef Medline

Keating JG, Thach WT (1995) Nonclock behavior of inferior olive neurons: interspike interval of Purkinje cell complex spike discharge in the awake behaving monkey is random. J Neurophysiol 73:1329-1340. Medline

Kobayashi Y, Kawano K, Takemura A, Inoue Y, Kitama T, Gomi H, Kawato M (1998) Temporal firing patterns of Purkinje cells in the cerebellar ventral paraflocculus during ocular following responses in monkeys: II. Complex spikes. J Neurophysiol 80:832-848. Medline

Kuiper NH (1960) Tests concerning random points on a circle. P K Ned Akad Wetensc 63:38-47.

Kusunoki M, Kano M, Kano MS, Maekawa K (1990) Nature of optokinetic response and zonal organization of climbing fiber afferents in the vestibulocerebellum of the pigmented rabbit: I. The flocculus. Exp Brain Res 80:225-237. Medline

Leonard CS, Simpson JI (1986) Simple spike modulation of floccular Purkinje cells during the reversible blockade of their climbing fiber afferents. In: Adaptive processes in visual and oculomotor system (Keller EL, Zee DS, eds), pp 429-434. Oxford, United Kingdom: Pergamon.

Leonard CS, Simpson JI, Graf W (1988) Spatial organization of visual messages of the rabbit's cerebellar flocculus: I. Typology of inferior olive neurons of the dorsal cap of Kooy. J Neurophysiol 60:2073-2090. Medline

Mardia KV, Jupp PE (1999) Directional statistics. Chichester, United Kingdom: Wiley.

Marr D (1969) A theory of cerebellar cortex. J Physiol 202:437-470. Medline

McCrea RA, Baker R (1985) Anatomical connections of the nucleus prepositus of the cat. J Comp Neurol 237:377-407. CrossRef Medline

McFarland JL, Fuchs AF (1992) Discharge patterns in nucleus prepositus hypoglossi and adjacent medial vestibular nucleus during horizontal eye movement in behaving macaques. J Neurophysiol 68:319-332. Medline

Medina JF, Nores WL, Mauk MD (2002) Inhibition of climbing fibres is a signal for the extinction of conditioned eyelid responses. Nature 416:330 333. CrossRef Medline

Miall RC, Weir DJ, Wolpert DM, Stein JF (1993) Is the cerebellum a Smith predictor? J Mot Behav 25:203-216. CrossRef Medline

Miura A, Sato Y, Watanabe Y, Fushiki H, Kawasaki T (1993) Direction selective climbing fiber responses to horizontal and vertical optokinetic stimuli in the cat cerebellar flocculus. Acta Otolaryngol Suppl 504:17-20. Medline

Mizuno N, Nakamura Y, Iwahori N (1974) An electron microscope study of the dorsal cap of the inferior olive in the rabbit, with special reference to the pretecto-olivary fibers. Brain Res 77:385-395. CrossRef Medline

Mustari MJ, Fuchs AF (1990) Discharge patterns of neurons in the pretectal nucleus of the optic tract (NOT) in the behaving primate. J Neurophysiol 64:77-90. Medline

Mustari MJ, Fuchs AF, Kaneko CR, Robinson FR (1994) Anatomical connections of the primate pretectal nucleus of the optic tract. J Comp Neurol 349:111-128. CrossRef Medline

Oscarsson O (1980) Functional organization of olivary projection to the cerebellar anterior lobe. In: The inferior olivary nucleus: anatomy and physiology (Courville J, De Montigni C, Lamarre Y, eds), pp 279-289. New York: Raven.

Quinn KJ, Schmajuk N, Baker JF, Peterson BW (1992) Simulation of adaptive mechanisms in the vestibulo-ocular reflex. Biol Cybern 67:103-112. CrossRef Medline

Raymond JL, Lisberger SG, Mauk MD (1996) The cerebellum: a neuronal learning machine? Science 272:1126-1131. CrossRef Medline

Robinson DA (1963) A method of measuring eye movement using a scleral search coil in a magnetic field. IEEE Trans Biomed Eng 10:137-145. Medline

Robinson DA (1976) Adaptive gain control of vestibuloocular reflex by the cerebellum. J Neurophysiol 39:954-969. Medline

Sato Y, Miura A, Fushiki H, Kawasaki T (1992) Short-term modulation of cerebellar Purkinje cell activity after spontaneous climbing fiber input. J Neurophysiol 68:2051-2062. Medline

Sears LL, Steinmetz JE (1991) Dorsal accessory inferior olive activity diminishes during acquisition of the rabbit classically conditioned eyelid response. Brain Res 545:114-122. CrossRef Medline

Shelhamer M, Tiliket C, Roberts D, Kramer PD, Zee DS (1994) Short-term vestibulo-ocular reflex adaptation in humans: II. Error signals. Exp Brain Res 100:328-336. Medline 
Shidara M, Kawano K, Gomi H, Kawato M (1993) Inverse-dynamics model eye movement control by Purkinje cells in the cerebellum. Nature 365: 50-52. CrossRef Medline

Simpson JI, Alley KE (1974) Visual climbing fiber input to rabbit vestibulocerebellum: a source of direction-specific information. Brain Res 82:302308. CrossRef Medline

Simpson JI, Leonard CS, Soodak RE (1988) The accessory optic system of rabbit: II. Spatial organization of direction selectivity. J Neurophysiol 60:2055-2072. Medline

Simpson JI, Wylie DR, De Zeeuw CI (1996) On climbing fiber signals and their consequence(s). Behav Brain Sci 19:380-394.

Simpson JI, Belton T, Suh M, Winkelman B (2002) Complex spike activity in the flocculus signals more than the eye can see. Ann N Y Acad Sci 978:232-236. CrossRef Medline

Soetedjo R, Fuchs AF (2006) Complex spike activity of Purkinje cells in the oculomotor vermis during behavioral adaptation of monkey saccades. J Neurosci 26:7741-7755. CrossRef Medline

Soodak RE, Simpson JI (1988) The accessory optic system of rabbit: I. Basic visual response properties. J Neurophysiol 60:2037-2054. Medline

Stahl JS, Simpson JI (1995) Dynamics of abducens nucleus neurons in the awake rabbit. J Neurophysiol 73:1383-1395. Medline

Stone LS, Lisberger SG (1990) Visual responses of Purkinje cells in the cerebellar flocculus during smooth-pursuit eye movements in monkeys: II. Complex spikes. J Neurophysiol 63:1262-1275. Medline

Tabata H, Yamamoto K, Kawato M (2002) Computational study on monkey VOR adaptation and smooth pursuit based on the parallel controlpathway theory. J Neurophysiol 87:2176-2189. Medline

Takeda T, Maekawa K (1976) The origin of the pretecto-olivary tract: a study using the horseradish peroxidase method. Brain Res 117:319-325. CrossRef Medline

Tan J, Gerrits NM, Nanhoe R, Simpson JI, Voogd J (1995) Zonal organization of the climbing fiber projection to the flocculus and nodulus of the rabbit: a combined axonal tracing and acetylcholinesterase histochemical study. J Comp Neurol 356:23-50. CrossRef Medline

Thach WT Jr (1967) Somatosensory receptive fields of single units in cat cerebellar cortex. J Neurophysiol 30:675-696. Medline

Van der Steen J, Simpson JI, Tan J (1994) Functional and anatomic organization of three-dimensional eye movements in rabbit cerebellar flocculus. J Neurophysiol 72:31-46. Medline

Wentzel PR, Wylie DR, Ruigrok TJ, De Zeeuw CI (1995) Olivary projecting neurons in the nucleus prepositus hypoglossi, group y and ventral dentate nucleus do not project to the oculomotor complex in the rabbit and the rat. Neurosci Lett 190:45-48. CrossRef Medline

Wilkie D (1983) Rayleigh test for randomness of circular data. Appl Stat 32:311-312. CrossRef

Winkelman B, Frens M (2006) Motor coding in floccular climbing fibers. J Neurophysiol 95:2342-2351. Medline

Wolpert DM, Miall RC (1996) Forward models for physiological motor control. Neural Netw 9:1265-1279. CrossRef Medline

Wolpert DM, Miall RC, Kawato M (1998) Internal models in the cerebellum. Trends Cogn Sci 2:338-347. CrossRef Medline

Yakusheva T, Blazquez PM, Angelaki DE (2010) Relationship between complex and simple spike activity in macaque caudal vermis during three-dimensional vestibular stimulation. J Neurosci 30:8111-8126. CrossRef Medline

Yin TC, Kuwada S (1983) Binaural interaction in low-frequency neurons in inferior colliculus of the cat: III. Effects of changing frequency. J Neurophysiol 50:1020-1042. Medline 